\title{
The time course of the use of implicit causality information in the processing of pronouns: A visual world paradigm study
}

\author{
Reinier Cozijn ${ }^{\mathrm{a}, *}$, Edwin Commandeur ${ }^{\mathrm{a}, 1}$, Wietske Vonk ${ }^{\mathrm{b}, \mathrm{c}}$, Leo G.M. Noordman ${ }^{\mathrm{a}, \mathrm{d}}$ \\ a Tilburg Center for Cognition and Communication, Tilburg University, The Netherlands \\ ${ }^{\mathrm{b}}$ Max Planck Institute for Psycholinguistics, Nijmegen, The Netherlands \\ ${ }^{\mathrm{c}}$ Centre for Language Studies, Radboud University Nijmegen, The Netherlands \\ ${ }^{\mathrm{d}}$ Donders Institute for Brain, Cognition, and Behaviour, Radboud University Nijmegen, The Netherlands
}

\section{A R T I C L E I N F O}

\section{Article history:}

Received 3 November 2009

revision received 18 December 2010

\section{Keywords:}

Language comprehension

Visual world paradigm

Implicit causality

Pronoun resolution

\begin{abstract}
A B S T R A C T
Several theoretical accounts have been proposed with respect to the issue how quickly the implicit causality verb bias affects the understanding of sentences such as "John beat Pete at the tennis match, because he had played very well". They can be considered as instances of two viewpoints: the focusing and the integration account. The focusing account claims that the bias should be manifest soon after the verb has been processed, whereas the integration account claims that the interpretation is deferred until disambiguating information is encountered. Up to now, this issue has remained unresolved because materials or methods have failed to address it conclusively. We conducted two experiments that exploited the visual world paradigm and ambiguous pronouns in subordinate because clauses. The first experiment presented implicit causality sentences with the task to resolve the ambiguous pronoun. To exclude strategic processing, in the second experiment, the task was to answer simple comprehension questions and only a minority of the sentences contained implicit causality verbs. In both experiments, the implicit causality of the verb had an effect before the disambiguating information was available. This result supported the focusing account.
\end{abstract}

(c) 2011 Elsevier Inc. All rights reserved.

\section{Introduction}

When hearing or reading a sentence, several sources of information are used to achieve understanding. The comprehension process calls upon linguistic knowledge about phonological, syntactic, semantic, and pragmatic characteristics of the input, as well as upon general knowledge about the state of affairs in the world the sentence relates to. Crucial to the comprehension process is the establishment of whom or what a sentence is about. Normally,

\footnotetext{
* Corresponding author. Address: Department of Communication and Information Sciences, School of Humanities, Tilburg University, P.O. Box 90153, 5000 LE Tilburg, The Netherlands. Fax: +31 134663110.

E-mail address: r.cozijn@uvt.nl (R. Cozijn).

${ }^{1}$ Present address: ATLIS, Bunnik, The Netherlands.
}

sentences are about their subjects, so the main clause of sentence (1) is about 'John', its subject.

(1) John beat Pete at the tennis match, because he had played very well.

(2) John beat Pete at the tennis match, because he had been ill all week.

However, it is less obvious whom the subordinate clause is about. The subject of the subordinate clause is 'he', a pronoun, referring to an entity mentioned earlier in the discourse. Understanding this clause and, consequently, the complete sentence entails resolving whom 'he' refers to. Unfortunately, the pronoun is ambiguous, since both entities in the discourse, 'John' and 'Pete', are male. There are, however, several other sources of information available to the comprehender to resolve this issue. 
First, using a general cognitive processing strategy (Gernsbacher, 1990), the comprehender might interpret the pronoun as referring to 'John', simply because he is mentioned first in the main clause. Second, the comprehender might be guided by a subject preference, that is, the preference to assign the referent of a pronoun to the subject of the preceding sentence (Hobbs, 1979), and assign the referent to 'John', the subject of the preceding clause. Third, in accordance with a syntactic, parallel processing strategy (Sheldon, 1974), the noun phrase 'John' might be considered the preferred referent because it is, like 'he', subject of its clause. Fourth, there is a preference for 'John' because people have a preference to attribute the cause of this event to the winner and not to the loser. The preference language users have to attribute the causes of events described by some interpersonal verbs either to the subject or to the object of the clause containing the verb is called the implicit causality bias (Caramazza, Grober, Garvey, \& Yates, 1977; Garvey \& Caramazza, 1974).

The information sources mentioned in this example all point to 'John' as the preferred referent for the ambiguous pronoun 'he'. However, it should be clear, that none of these sources is conclusive with respect to the definite resolution of the pronoun. A definitive answer to whom 'he' refers cannot be given until all sentence information has been obtained. The subordinate clause ends stating that 'he' had played very well, and our knowledge about winning and losing tennis matches dictates that playing well is a suitable reason for winning but not for losing a tennis match. In the end, therefore, the comprehension of the sentence results in a representation in which 'he' is resolved as referring to 'John' and not to 'Pete', since it was 'John' who won the match, given that 'Pete' was beaten. The subordinate clause is congruent with an interpretation that the cause of the event in the main clause is attributed to 'John'. In (2), on the other hand, the subordinate clause is incongruent with this interpretation. Our world knowledge dictates that being ill is a suitable reason for losing a game but not for winning. Therefore, the final interpretation of sentence (2) should be that the cause of 'beating' is attributed to the protagonist in the main clause who is losing and, consequently, that 'he' refers to 'Pete'. Reading times for incongruent sentences and naming times for the referent of incongruent sentences are longer than for congruent sentences (Caramazza et al., 1977; Garvey \& Caramazza, 1974; Vonk, 1985). This effect is called the congruency effect.

Verbs like 'to beat' systematically invite an explanation from the perspective of the subject of the clause. Verbs that induce a preference for the attribution of the cause to the subject, the first Noun Phrase, are called NP1-verbs. Other verbs, like 'feel sorry for someone', show exactly the opposite tendency and induce a preference for the attribution of the cause to the object of the main clause, the second Noun Phrase. So, a sentence like 'John felt sorry for Pete after the exam, because' is preferentially completed with the attribution of the cause to the object noun phrase as, for instance, 'he did not receive a good grade'. These verbs are called NP2-verbs.

Over the past decades, implicit causality has been investigated extensively by psychologists, linguists, and psycholinguists, and the overall conclusion that can be drawn from these studies is that it is a robust and strong phenomenon (see, for instance, Rudolph \& Försterling, 1997). From a psycholinguistic point of view, the interest in implicit causality lies in its influence on ongoing language comprehension processes. Most notably, its influence has been investigated on the processes of pronoun resolution. Given that sentences with an implicit causality verb elicit a causal continuation with reference to either the subject or the object of the main clause, it is assumed that the verb supplies a bias for one of the protagonists.

By using sentences like (1) and (2), a number of studies have investigated the influence of implicit causality on sentence processing (Caramazza et al., 1977; Garnham, 2001; Garnham, Traxler, Oakhill, \& Gernsbacher, 1996; Greene \& McKoon, 1995; Koornneef \& Van Berkum, 2006; Long \& De Ley, 2000; Stewart, Pickering, \& Sanford, 2000; Vonk, 1985). These studies manipulated the congruency of the information in the subordinate clause with the implicit causality bias of the verb, as explained above, and the congruency of the pronoun in the subordinate clause. By using protagonists of different gender, pronouns refer unambiguously to one of them. An example is given in (3).

(3) John beat Mary at the tennis match, because she had been ill all week.

In psycholinguistic research on implicit causality, the issue of the time course of information use is pinned down to determining at what moment during sentence processing the verb bias exerts its influence on the assignment of a referent to the pronoun. Essentially, there are two viewpoints. The first viewpoint is propagated by accounts that claim that the implicit causality bias affects the availability of one of the protagonists in the event described by the verb before disambiguating information is available. The bias brings the protagonist in focus, as it were, and when a pronoun is encountered, the biased protagonist is considered to be the preferred referent. Several accounts have been proposed that concur with this viewpoint: the anticipation account (McDonald \& MacWhinney, 1995), the focusing account (Garnham et al., 1996; Long \& De Ley, 2000; Stewart et al., 2000), and the 'truly' proactive anticipation account (Koornneef \& Van Berkum, 2006). For the present purposes these accounts are considered as instances of the focusing hypothesis even though they differ in the assumed underlying proactive mechanism. This viewpoint will be referred to by the term focusing account throughout this paper.

The second viewpoint states that the implicit causality bias has no effect until disambiguating information is obtained. Normally, that happens when all information contained in the clauses has been processed and the clausal relation, as indicated by the connective, is integrated (cf. Hobbs, 1979; Traxler, Bybee, \& Pickering, 1997). This is in line with the notion, mentioned above, that the definite resolution of pronouns cannot occur before all information has been obtained, which normally is at sentence ending. The second viewpoint has been called (clausal) integration account or retroactive account in the literature (Garnham et al., 1996; Koornneef \& Van Berkum, 2006; Long \& De 
Ley, 2000; Stewart et al., 2000), and will be referred to by the term integration account throughout this paper.

It should be clear that the focusing account does not rule out congruency effects at sentence endings, since any pronoun assignment still has to be finalized when all sentence information has become available. The main difference between the two accounts, therefore, is that the focusing account, unlike the integration account, assumes that since the bias of the verb has an immediate impact on the accessibility of one of the protagonists, that is, bringing it into focus, its influence should be detectable before any disambiguating information has been given.

Several studies have been conducted to resolve this issue. Garnham et al. (1996) used a probe recognition task to find early effects of an implicit causality bias. The probes consisted of the names of the protagonists and were presented at several points during a word-by-word, machine-paced visual presentation of the sentences. The task was to state as quickly as possible whether the sentence so far had contained the probe name. The speed of responding to the task was believed to be an indication of the availability of the referent in memory. They failed to find early effects of implicit causality, but they did find late effects, at the end of processing the sentence. They interpreted these results as evidence for the integration account. Long and De Ley (2000), on the other hand, used the same task and did find an early effect of the implicit causality bias on the processing of gender contrastive pronouns. McDonald and MacWhinney (1995) used gender contrastive and gender neutral pronouns. They presented the probes visually and the sentences aurally. The results of their experiments were in support of the focusing account, showing early effects of verb bias.

The conflicting results may be due to problems associated with the probe recognition task. A problem with the task, apart from its unnaturalness, is that it is a doubletask, and as such increases the cognitive load of the participants. This is the more so when the probes are presented in the same modality as the sentence. Effects of verb bias on the probe response times might be obscured by this extra processing burden. Another problem has been raised by Gordon, Hendrick, and Foster (2000). They showed that probe recognition times might be explained by a probe-list memory strategy of the participants, that is, keeping track of those words that are believed to be likely to be probed. The probe recognition task, therefore, has many caveats and leaves the issue of determining at what moment during sentence processing the verb bias exerts its influence on the assignment of a referent to the pronoun unresolved.

A less burdensome and potentially more sensitive method is the registration of reading times. If implicit causality conflicts with pronoun gender, as explained above, reading times should be longer than if no conflict arises. Stewart et al. (2000) varied the gender of the pronoun and presented the implicit causality sentences subjectpaced in two parts. The first part consisted of the implicit causality clause up to and including the pronoun. The second part contained the rest of the sentence. They obtained evidence for a congruency effect on the reading times of the second part of the sentence, but not on those of the first. They concluded that implicit causality does not affect the processing of pronouns but only sentence integration. A problem in their experiment is that the pronouns were presented as the last word of the first part of the sentence. It may be assumed that possible effects of congruency on the pronoun are too small to make a difference significantly noticeable in the clause reading times. Furthermore, their method does not exclude the possibility that an effect of congruency on the pronoun might have spilled over to the second part of the sentence, where an effect of congruency was found. To avoid these problems, Koornneef and Van Berkum (2006) reverted to word-by-word, self-paced reading times and eye-movement registration to study the comprehension process. In two experiments, they found evidence for an early effect of an implicit causality bias on the processing of sentences containing unambiguous pronouns. They found a significant difference in the reading times on the words immediately following the pronoun. The reading times of these words were longer in the incongruent condition than in the congruent condition, indicating an early effect of the implicit causality bias (see also Featherstone \& Sturt, 2010). Furthermore, Van Berkum, Koornneef, Otten, and Nieuwland (2007) found converging results in an ERP study. They showed that the incongruency of the pronoun resulted in a P600 which they interpret as a signal of early, syntactic processing difficulties. (However, the functional significance of the P600 is under debate and is believed to reflect some kind of revision or repair of the sentence; (see, for instance, Van Herten, Kolk, \& Chwilla, 2005).

The studies conducted thus far yield conflicting results. Some are in favor of the integration account and others of the focusing account, and although Koornneef and Van Berkum (2006) and Van Berkum et al. (2007) take their data to support the latter, their interpretation of the results is problematic. The problem lies in their use of unambiguous pronouns. As Garnham et al. (1996) pointed out, integration takes place as soon as disambiguating information is encountered. Unambiguous pronouns provide such information: "When the pronoun cannot be resolved from its morphology, information about its congruity becomes available only toward the end of the subordinate clause and, thus, congruity effects can manifest themselves only when the end of the clause is read. However, when the form of the pronoun determines its referent, and hence whether the subordinate clause is congruent with the bias of the previous verb, congruity effects, or more likely referent effects, should manifest themselves at that point" (p. 521). The findings of Koornneef and Van Berkum (2006) and Van Berkum et al. (2007), therefore, might be considered evidence for the integration account instead of evidence for the focusing account.

It seems then that support for the focusing account should be sought in establishing that implicit causality biases the processing of ambiguous pronouns. However, this is not a trivial problem. The methods used thus far do not seem to be sensitive to (shifts in) focus without disturbing the comprehension process. As explained above, the probe recognition task has been shown to be unnatural and too insensitive, and it is hard to conceive how reading time differences, and for that matter, ERP measures, might reveal the dominance of one referent over another when 
participants read or listen to discourse with an ambiguous pronoun The method used here is the visual world paradigm (Altmann \& Kamide, 2004; Cooper, 1974; Tanenhaus, Spivey-Knowlton, Eberhard, \& Sedivy, 1996), a method that indeed might reveal this dominance.

Vision typically reveals attention guiding processes: What is being looked at is, in general, what is being processed (see Irwin, 2004, for a review of the correspondence between eye movements and attention). This characteristic allows for the study of the volatile and notoriously difficult to measure notion of 'focusing' (Stevenson, Knott, Oberlander, \& McDonald, 2000). The present study utilizes this characteristic to investigate how and when an implicit causality bias of verbs influences the focus of listeners while processing sentences containing implicit causality verbs. Participants listen to these sentences while they look at a visual scene that depicts the protagonists of the sentence. Their eye movements are expected to reveal which protagonist is in focus while the sentence is being processed.

According to the focusing account, there should be more eye movements to the biased protagonist than to the nonbiased protagonist before the disambiguating information in the subordinate clause is encountered. These eye movements might already reveal a dominance of the biased referent when the conjunction 'because' or the ambiguous pronoun is being processed. The integration account does not predict any differences before the disambiguating information is encountered. At the end of the sentence when either bias-congruent or bias-incongruent information is presented, the eye movements should reveal the definite outcome of the pronoun resolution process. Both accounts predict congruency effects at this point.

The eye movements might reveal the influence of other information sources as well, such as first mention, subject bias, and parallel processing, which show a bias toward the subject or the first-mentioned protagonist of the first clause when the second clause is presented (Gernsbacher, 1990; Gordon, Grosz, \& Gilliom, 1993; Järvikivi, Van Gompel, Hyönä, \& Bertram, 2005; Sheldon, 1974). In the present study, these factors have not been varied: In all implicit causality sentences used, the subject of the main clause coincided with the first-mention position. These structure related factors will be called first mention throughout this paper.

The focusing versus integration accounts have been tested in two visual world paradigm experiments. In the first experiment participants named the referent of the pronoun at the end of the sentence. In the second experiment, filler sentences were used and a task that was unrelated to resolving pronouns.

\section{Experiment 1}

\section{Method}

\section{Participants}

Forty students of the Radboud University Nijmegen participated in the experiment (19 male and 21 female, mean age 22 years). They were native speakers of Dutch and reported to have normal hearing and normal or corrected to normal vision (five participants had lenses). The data of two participants were excluded from further analysis, because of poor data quality due to excessive blinking and/ or staring. Thus, there were 38 participants in the analysis.

\section{Materials}

Auditory stimuli were constructed that were sentences consisting of a main biasing clause with an implicit causality verb and two protagonists, a subordinate causal neutral clause, and a subordinate causal disambiguating clause (see Table 1). The visual stimuli were cartoon drawings of the two protagonists of the main clause together with a distractor object (see Fig. 1; originally hand drawn by the second author).

The biasing clause expressed a relation between two protagonists with an implicit causality verb that either induced a preference for the attribution of the cause to the subject of the clause, the first protagonist (NP1), or to the object of the clause, the second protagonist (NP2). The clause ended with a prepositional phrase describing a distractor object. The function of the distractor was to divert the attention away from the protagonists before the onset of the pronoun in the first subordinate clause. The subordinate clauses started with the causal conjunction 'omdat' (because) and the pronoun 'hij' (he) and expressed a cause of the event of the main clause. In Dutch, the two pronouns of the two subordinate clauses co-refer, unless one of the pronouns is prosodically marked.

The first subordinate clause, the neutral clause, was uninformative with respect to the resolution of the pronoun: It supported an NP1 and an NP2 reading of the pronoun equally well. The inclusion of the neutral clause extended the range within which an effect of implicit causality bias could be detected before disambiguating information was given. In addition, the implicit causality congruency effect has been found to be larger when there is a neutral clause between the biasing clause and the disambiguating clause than when the biasing clause is directly followed by the disambiguating clause (Vonk, 1985). The interpretation of this result was that the effect of the bias was already established during the neutral clause. The disambiguating information was supplied in the second subordinate clause in two versions, one that was congruent with the implicit causality bias of the verb in the main clause and one that was incongruent with the implicit causality bias of this verb. Thus, the subordinate disambiguating clauses disambiguated the sentences either to an NP1 reading or to an NP2 reading of the pronoun. With the exception of two sentences in which the disambiguating information was expressed by two words, the disambiguating information consisted of one word. These words will be referred to as the disambiguating words. The disambiguating clause ended with a prepositional phrase that contained no disambiguating information.

An equal number of congruent and incongruent sentences were used, since the use of only congruent sentences may lead to a strategy of the participants to capitalize on the implicit causality bias information (Garnham, 2001).

For each sentence pair, congruent and incongruent, one visual stimulus was created. The stimulus displayed the two protagonists and the distractor object of the corre- 
Table 1

Example of an experimental sentence with an NP1-verb and an NP2-verb in the congruent and the incongruent condition. The regions of the sentences are coded in subscript and the disambiguating word is in bold (English translations in Dutch word order are in italics).

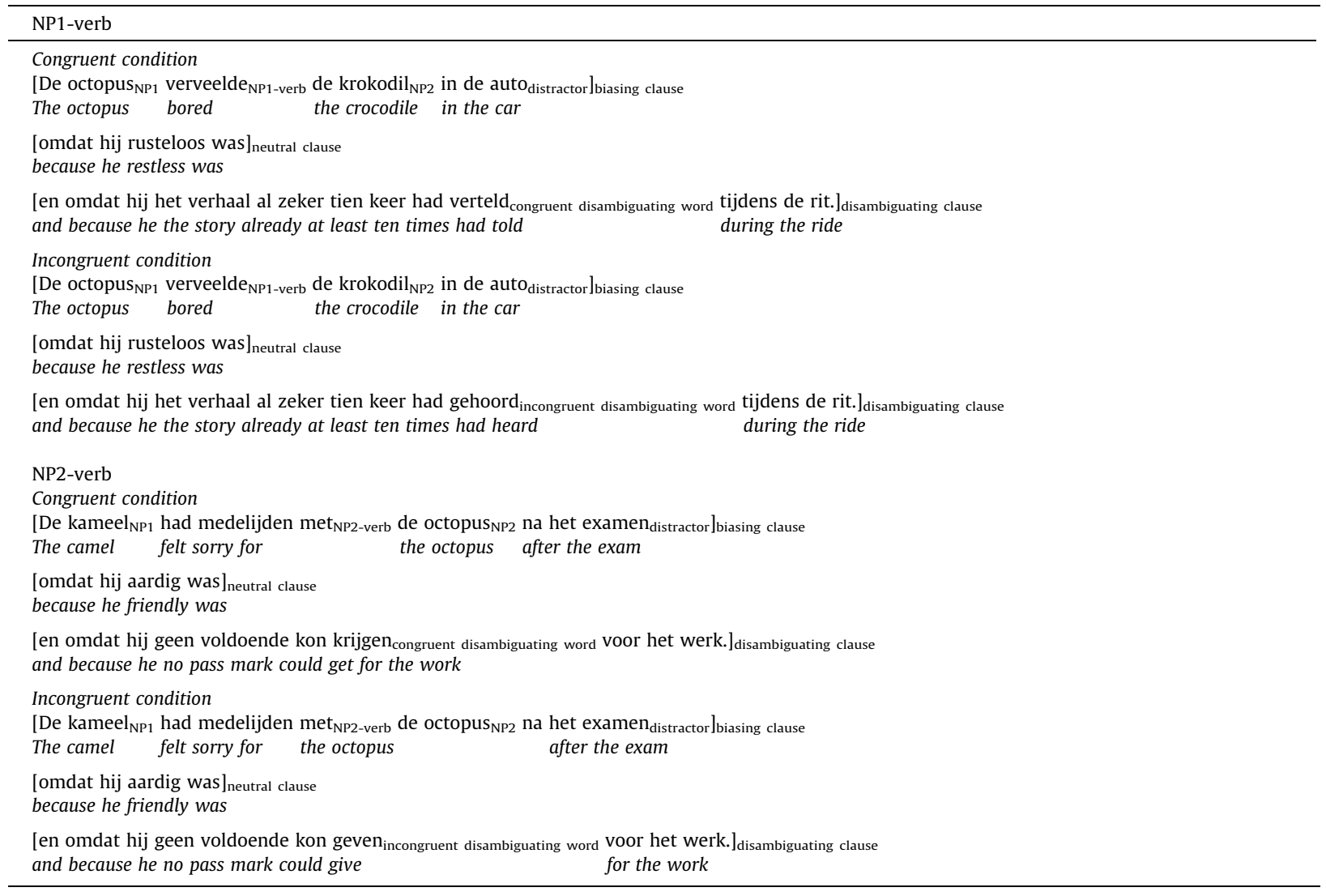

sponding sentence. The protagonists were animals, because animals are easy to depict and highly recognizable. In addition, animals are not readily associated with a social status. Social status of the participants might influence the strength and even the direction of the implicit causality bias (Corrigan, 1993, 2001; Garvey, Caramazza, \& Yates, 1974-1975).
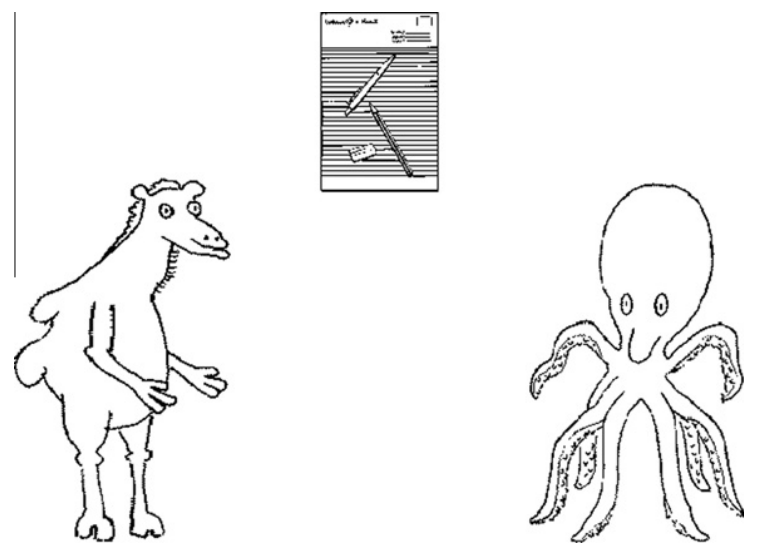

Fig. 1. Example of a visual stimulus (vector traces of the original bitmap images). The three figures represent a camel, an octopus, and a piece of paper with pencils and an eraser representing the distractor 'the exam' (see Table 1 for the corresponding sentences; Experiment 1).
In Experiment 1, eight sentence pairs with an NP1-verb and eight sentence pairs with an NP2-verb and 16 different pictures with 32 different animal protagonists were used. The experimental materials were selected on the basis of three pre-tests. The first pre-test examined the strength of the implicit causality verbs. The second pre-test determined whether the animal protagonists could easily be recognized and named and whether they were referred to by the pronoun 'he'. The third pre-test established whether the constructed neutral clauses were indeed neutral and the constructed disambiguating clauses indeed disambiguating. The participants in the three pre-tests were undergraduate students of Tilburg University. In each pre-test, different students participated and they were different from the participants in Experiments 1 and 2.

Pre-test 1. The first pre-test was a fragment completion task. An initial set of 44 sentence fragments was constructed each with an implicit causality verb. The template for the fragments was 'NP1 verbed NP2, because he. ..' The protagonists in these fragments were always two males referred to by common Dutch male proper names. Only male proper names were used, because the Dutch pronoun 'zij' is ambiguous between a female singular reading (she) and a plural reading (they). An example of a sentence fragment is given in (4). 
(4) Jan dwarsboomde Piet, omdat hij... John thwarted Pete, because he...

One hundred and two participants completed the fragments to a full sentence. The study resulted in the selection of 32 verbs for further pre-testing: 16 verbs which strongly biased causal attributions to the NP1 and 16 verbs which strongly biased causal attributions to the NP2. The data for the selected items of this pre-test are presented after the description of pre-test 3 .

Pre-test 2 . The second pre-test was a story elicitation task. Cartoons of 38 different animals were drawn and were combined in 19 pictures of two animals. Thirty participants were presented with a number of pictures, each picture being accompanied by a set of five key phrases (e.g., cartoons of an ostrich and a mouse together with the phrases 'play a game', 'win', 'angry', 'throw', and 'search'). The task was to make up a story of several sentences about the animals using the key phrases. The pre-test resulted in 32 animals that could easily be recognized and named and that were reliably referred to with the pronoun 'he'.

Pre-test 3. The third pre-test was a referent judgment task. For each of the 32 implicit causality verbs, three sentences were constructed. These sentences had the same main clause and a different subordinate causal clause. The subordinate clause contained the pronoun 'he' and was supposed to be either neutral, or congruent, or incongruent with respect to the implicit causality bias of the verb in the main clause. In this pre-test, the animal names selected in pre-test 2 were used. An example of an NP1-biasing verb in the main clause and an incongruent subordinate clause is (5).

(5) De octopus verveelde de krokodil in de auto, omdat hij het verhaal al zeker tien keer had gehoord. The octopus bored the crocodile in the car, because he the story already at least ten times had heard.

See Table 1 for other example clauses. Forty participants had to determine for each sentence which animal the pronoun referred to (either NP1 or NP2), and to specify how certain they were about their answer. There were three blocks of 32 sentences, each block containing the 32 different main clauses with a subordinate clause. A block contained 10 or 11 of each kind of subordinate clause (neutral, congruent, incongruent). A neutral clause was considered neutral if the choice of the 'correct' referent was close to $50 \%$ and participants were not very certain about their choice. A disambiguating clause was considered disambiguating if in the large majority of cases the intended referent was chosen and participants were certain about their choice.

The pre-tests 1 and 3 resulted in the selection of 8 NP1 items and 8 NP2 items, an item consisting of a main clause with one of the 16 implicit causality verbs, combined with a neutral and a congruent subordinate clause or a neutral and an incongruent subordinate clause. The selected verbs are presented in Appendix A. In pre-test 1, the selected
NP1-verbs had 92\% NP1 continuations (range: 86-99\%) and the selected NP2-verbs had 81\% NP2 continuations (range: 75-92\%). In pre-test 3, the neutral, congruent, and incongruent subordinate clauses obtained the following referent (percentages NP1 or NP2-referent) and certainty scores (either certain, 1 , or uncertain, 0 ). For neutral clauses, $62 \%$ of the participants chose the NP1referent if the sentence contained an NP1-verb, with certainty score .44 and $52 \%$ of the participants chose the NP2-referent if the sentence contained an NP2-verb with certainty score .50. For NP1-verb congruent clauses, the intended referent for the pronoun (NP1) had been chosen in $92 \%$ of the cases with certainty score .86 , and for NP1-verb incongruent clauses, the intended referent (NP2) had been chosen in $89 \%$ of the cases with certainty score .82 . For NP2-verb congruent clauses, the intended referent (NP2) had been chosen in $96 \%$ of the cases with certainty score .91 , and for NP2-verb incongruent sentences, the intended referent (NP1) had been chosen in 94\% of the cases with certainty score .87 .

The 32 different animals selected in pre-test 2 were presented only once in the set of 16 experimental sentences a participant heard and saw.

In addition to the 16 experimental items, there were seven other sentences selected from the pre-tests for practice and warm up items (a main clause and a neutral clause combined either with a congruent clause or with an incongruent clause).

The preparation of auditory stimuli. The 16 experimental sentence pairs and the seven extra sentence pairs were recorded in a single session in a sound proof booth. The speaker was a female native speaker of Dutch, who was naive with respect to the goal of the experiment. She was instructed to speak at a quiet pace using natural intonation, while avoiding emphasis on one or both of the protagonists, and not to start reading out loud until she had read and fully understood each sentence. The sentences were recorded in a pseudo-random order with regard to the implicit causality bias. No more than three items with the same verb bias were presented consecutively. The congruent and incongruent versions of each sentence were recorded after each other. Each sentence was recorded twice.

For each pair of congruent and incongruent sentences, one token was selected such that there were equal numbers of the originally congruent and originally incongruent recordings within the NP1-verb condition as well as within the NP2-verb condition. The criterion for the selection of tokens was that they were pronounced at a comfortable pace and that there was no emphasis of one protagonist over the other, according to three independent judges. The congruent and incongruent counterparts were constructed by splicing the appropriate disambiguating word into the selected tokens. These disambiguating words were taken from tokens in which the disambiguating word was acoustically most akin to the disambiguating clause of the selected tokens. The splicing procedure served to control for possible differences in prosody between congruent and incongruent stimuli before the onset of the disambiguating word. Splicing was performed using the program Praat (Boersma, 2001). 
The preparation of visual stimuli. The visual stimuli were black and white bitmap images with a size of 640 by 480 pixels. They portrayed two animals and a distractor object (see Fig. 1). The animals were cartoon style drawings of the protagonists in the auditory material. The distractor object was semantically related to the prepositional phrase in the biasing clause. The three figures were arranged in an isosceles triangle with the distractor object at the top and the animal cartoons at the bottom left and the bottom right. The distractor objects were 120 by 170 pixels in size and were positioned at screen coordinates 250, 20. The animal objects were 180 pixels wide and 300 high, and were positioned at coordinates 20, 160 , and 440,160 . Of each picture, a second version was created in which the animal cartoons had swapped places and were mirrored (such that the protagonists kept facing each other).

\section{Design}

Each of the 16 experimental items occurred in four conditions, depending on whether the disambiguating clause was congruent or incongruent and whether the NP1 protagonist was depicted at the bottom left position or the bottom right position in the visual stimulus. The resulting 64 experimental stimuli were distributed among four lists of 16 stimuli, in such a way that each item occurred once in each list. Each list contained four items in each of the four conditions. The order of the 16 experimental items was the same for all lists, but the conditions were distributed pseudo-randomly, with no more than three consecutive items that were identical with respect to verb bias, or with respect to congruency, or with respect to NP1-object position. Participants were assigned randomly to one of the four lists with 16 stimuli.

\section{Procedure}

Participants were seated approximately $70 \mathrm{~cm}$ from a $17^{\prime \prime}$ computer monitor in a dimly lit sound proof booth. The display monitor was set to a resolution of $640 \times 480$ pixels and a refresh rate of $60 \mathrm{~Hz}$. Eye movements were tracked with an SR Research Eyelink I eye tracker at a sampling rate of $250 \mathrm{~Hz}$. Calibration was performed before the practice session and before the experimental session, using a nine-point calibration procedure.

Before the actual experiment, there was a naming session to make sure that the participants were able to identify and name the animals used in the sentences. In order to conceal the interest in gaze direction, participants were told that the purpose of the experiment was to measure their pupil size (cf. Cooper, 1974), and that they had to keep their eyes on the computer screen for proper measurement. After the experiment, the true purpose of the experiment was revealed to them in a debriefing session. The participants were instructed to listen carefully to the sentences and, after each sentence, to say out loud the name of the animal they believed to be the referent of the pronoun 'he' in the sentence. It was stressed that it was more important to respond correctly than to respond fast.

After the head-mounted eye tracker had been installed and calibrated, a practice session of five trials followed.
Then the experiment started with two warm-up trials. Each trial began with a fixation star at the center of the screen. Participants had to actively fixate the center of the star and press a button on a button box to initiate the presentation of the next item. Immediately after the button had been pressed, the auditory stimulus was presented over the headphones simultaneously with the corresponding visual stimulus on the screen. After the offset of the auditory stimulus, the visual stimulus remained on the screen for another $200 \mathrm{~ms}$ and the participants had to say out loud the name of the animal the pronoun referred to. The trial ended upon a voice key trigger or after a timeout of two seconds post offset of the auditory stimulus. One second after trial termination, the central fixation star reappeared on the screen, indicating the start of the next trial. After three trials, a recalibration was performed. The recalibration consisted of a small circle at the center of the screen that had to be fixated accurately. The data obtained in the recalibration were used to correct possible linear shifts in measurement. The experiment lasted approximately $30 \mathrm{~min}$.

\section{Analysis}

The eye movements were parsed into saccades and fixations by the Eyelink software using the default settings.

The visual areas of analysis. There were four areas that participants could direct their attention to when looking at a stimulus: the NP1-area, the NP2-area, the distractor-area, and the background area. The NP1-, NP2-, and distractorareas corresponded to their object sizes (see section 'Preparation of the visual stimuli'). The background area was defined as the remaining area on the screen. The eyemovement analysis consisted of assigning the fixations to the areas. The analysis was performed automatically by the program Fixation ${ }^{2}$, and was checked manually.

The auditory segments of analysis. The auditory stimuli were divided into 11 consecutive segments of analysis. The 11 segments were the second protagonist in the biasing clause (NP2), the distractor segment (distractor), the pause after the first clause (pause 1 ), the connective and the pronoun of the neutral clause (conn + pro1), the remainder of the neutral clause (neutral clause), the pause after the neutral clause (pause2), the connective and the pronoun of the disambiguating clause (conn + pro2), the disambiguating clause up to the disambiguating word (pre_disamb), the disambiguating word (disamb), the remainder of the disambiguating clause (post_disamb), and a $500 \mathrm{~ms}$ segment after the end of the sentence (post_sentence). Since it takes around $200 \mathrm{~ms}$ to plan the launch of a saccade (Altmann \& Kamide, 2004), the earliest point at which fixations driven by a specific linguistic input can be expected to occur is $200 \mathrm{~ms}$ after the onset of the input. For that reason, the time interval that in the analysis is considered to correspond to an auditory segment has an onset and offset that is 200 ms later than the onset and

\footnotetext{
${ }^{2}$ A software tool developed at MPI Nijmegen and Tilburg University by the first author (Cozijn, 2006).
} 
offset of the auditory segment itself. The lengths of the segments of analysis prior to the onset of the disambiguating word were calculated by averaging the corresponding sentence fragment lengths for NP1-verb and NP2-verb sentences separately, and the lengths of the segments of analysis after the onset of the disambiguating word were calculated by averaging the corresponding sentence fragment lengths for NP1-verb congruent and incongruent sentences and for NP2-verb congruent and incongruent sentences separately. The lengths of the segments are presented in the Appendix B.

Measure of analysis. The measure of analysis is based on, but slightly differs from, the proportion of fixations measure as explained by Dahan and Tanenhaus (2004), which is sensitive to continuity in visual attention and reflects where participants are (and keep) looking during a given linguistic input segment. The main difference lies in the inclusion of the saccade preceding a fixation in the fixation count. The measure of analysis we use is defined as the eye movements up to the end of a fixation, starting at the end of the previous fixation. When both fixations are in the same area, blinks are included. When both fixations are in different areas and there is a blink in between the fixations, the fixation is discarded. Thus, most of the time the measure will consist of an in-saccade and a fixation, and sometimes, if the previous and the current fixation are in the same area, it will include a blink as well. The term 'fixation' does not cover the measure. We refer to the measure with the term 'look'. There is a good reason to pool insaccades with their succeeding fixations. Research by Irwin (2004) has shown that attention is generally directed to an object when making an in-saccade to that object and likely even before that. Blinks were included because it is assumed that the processing of the language stimuli continues during blinks (cf. Irwin, 2004; Vonk \& Cozijn, 2003). A look is assigned to the area that is fixated.

For the calculation of the measure, the eye-movement samples were first aligned to $200 \mathrm{~ms}$ after the onset of a segment of analysis. At consecutive 4-ms sample points relative to this alignment point, it was then determined at what area the participants were looking in each trial. The measure in an area at a specific sample point was defined as the number of looks at that area divided by the total number of looks at that sample point. The measures at each sample point sum up to one. To prepare the measure for statistical analysis, the looks at all sample points in a specific segment of analysis were averaged per area (cf. Altmann \& Kamide, 2004). The measure was calculated per condition for plotting, per condition and participant for statistical analyses by participants, and per condition and item for statistical analyses by items.

\section{Results}

The proportion of looks at the NP-areas of the protagonists were analyzed using repeated measures ANOVA. The two factors in the ANOVAs performed on the data for segments before the onset of the disambiguating word were Verbbias (NP1-verbs, NP2-verbs) and NP-area (NP1-area, NP2-area). From the disambiguating word onward, the sentences were either congruent or incongruent with the implicit causality bias, so a third factor, Congruency (congruent, incongruent), was added for segments that started after the onset of the disambiguating word. In the participant analyses ( $F 1)$, all factors were within variables. In the item analyses (F2), Verbbias was a between factor, NP-area a within factor, and Congruency was considered a between factor. The left-right position of the protagonists in the visual stimuli was not a factor in the statistical design; the data were averaged over the positions. Effects were only considered significant if they were significant by participants as well as by items. A MinF' was calculated on the basis of the analyses by participants and by items (Clark, 1973). Pairwise comparisons were performed on means obtained in the $F 1$ analyses as described by Bird (2002).

Prior to the onset of the disambiguating word, all data were entered into the analysis irrespective of whether the participants produced the correct protagonist, because early effects of implicit causality may exist regardless of whether participants are able to resolve the pronoun on the basis of the disambiguating information. After the onset of the disambiguating word, however, only trials in which the correct protagonist, the referent, had been produced were entered into the analysis. The error scores are reported in the section 'Segments of analysis after onset of disambiguating word'.

Segments of analysis before the onset of the disambiguating word

The focusing account predicts an interaction effect between Verbbias and NP-area before disambiguating information has been encountered. This interaction may occur as soon as the biasing clause has been perceived. The effect may, however, start at a later point and stretch throughout the sentence up to the disambiguating word, and, therefore, may appear in any of the segments following the pause up to the disambiguating word. The integration account, on the other hand, predicts no such effects.

In addition to the focusing hypothesis, several effects were expected for the segments before the onset of the disambiguating word. First, the auditory presentation of the NP2-protagonist should lead to more looks at the area depicting the NP2-protagonist than at the area of the NP1-protagonist. This effect simply would support the validity of the visual world paradigm. Second, at the time the distractor is presented, the advantage of the NP2-protagonist should have disappeared and no effect of NP-area should be found.

Fig. 2 shows the proportion of looks data over time at the NP1, the NP2, and the distractor for NP1-verbs and NP2-verbs before, during, and after the conn + pro1 segment, starting at $800 \mathrm{~ms}$ before the onset of the segment (as indicated by the zero) and ending at $1700 \mathrm{~ms}$ after the onset of the segment ${ }^{3}$. As explained in the section 'The auditory segments of analysis' above, the onset of the physical, auditory signal is at $0 \mathrm{~ms}$, but the segment itself

\footnotetext{
${ }^{3}$ For presentation purposes, the graphs in this figure, and in Fig. 5, were smoothed by averaging the looks of 11 consecutive $4 \mathrm{~ms}$ sample points and plotting the average over each sixth, central, sample point.
} 
has been analyzed starting $200 \mathrm{~ms}$ after onset and ending $200 \mathrm{~ms}$ after offset (see the grey area in the figure).

Visual inspection of the graph suggests that before onset of the conn + pro1 segment, there is a larger proportion of looks for the NP1-area than for the NP2-area in the NP1verb condition, whereas there are not more looks to the NP2-area than to the NP1-area in the NP2-verb condition. However, the graph suggests that the dominance of looks to the NP2-area over those to the NP1-area in the NP2-verb condition is established in the conn + pro1 segment and is maintained during the subsequent segment, that is, the neutral clause segment.
The average proportion of looks at the NP1-area, the NP2-area, and the distractor-area for the segments before the disambiguating word are plotted in Fig. 3, together with error bars representing the standard errors related to the difference between the proportions of looks at the NP1-area and the NP2-area (cf. Masson \& Loftus, 2003). The statistical tests for these segments, performed on the average proportions of looks per segment, are presented in Table 2.

In the con + pro1 segment, there was an interaction between Verbbias and NP-area: For NP1-verbs, there were more looks at the NP1-area than at the NP2-area

NP1-verbs
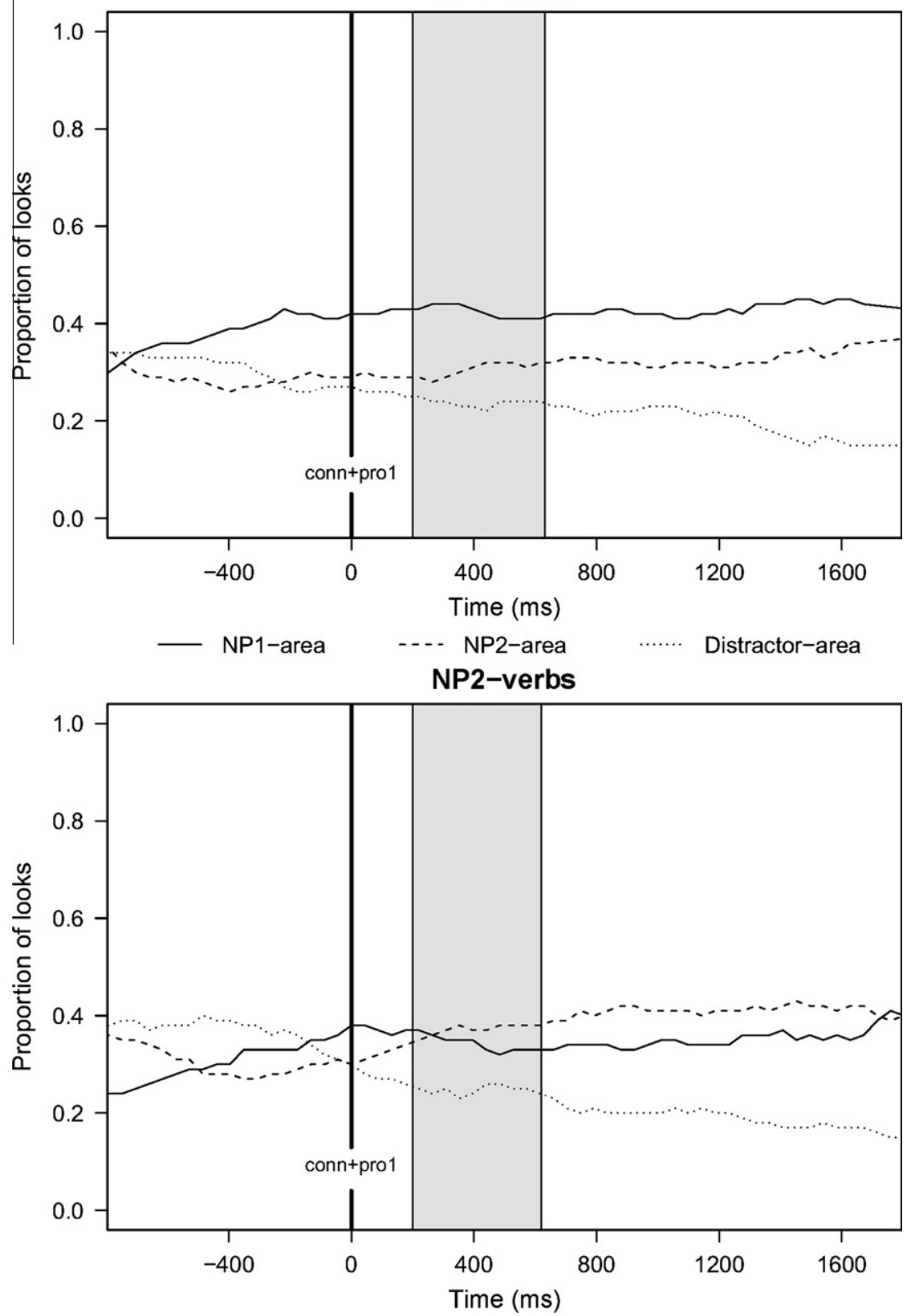

Fig. 2. Proportion of looks at the NP1-area, the NP2-area, and the Distractor-area in the NP1-verb (top) and NP2-verb (bottom) conditions for the conn + pro1 segment of analysis (grey area) in Experiment 1. The data are aligned to the onset of the connective. 

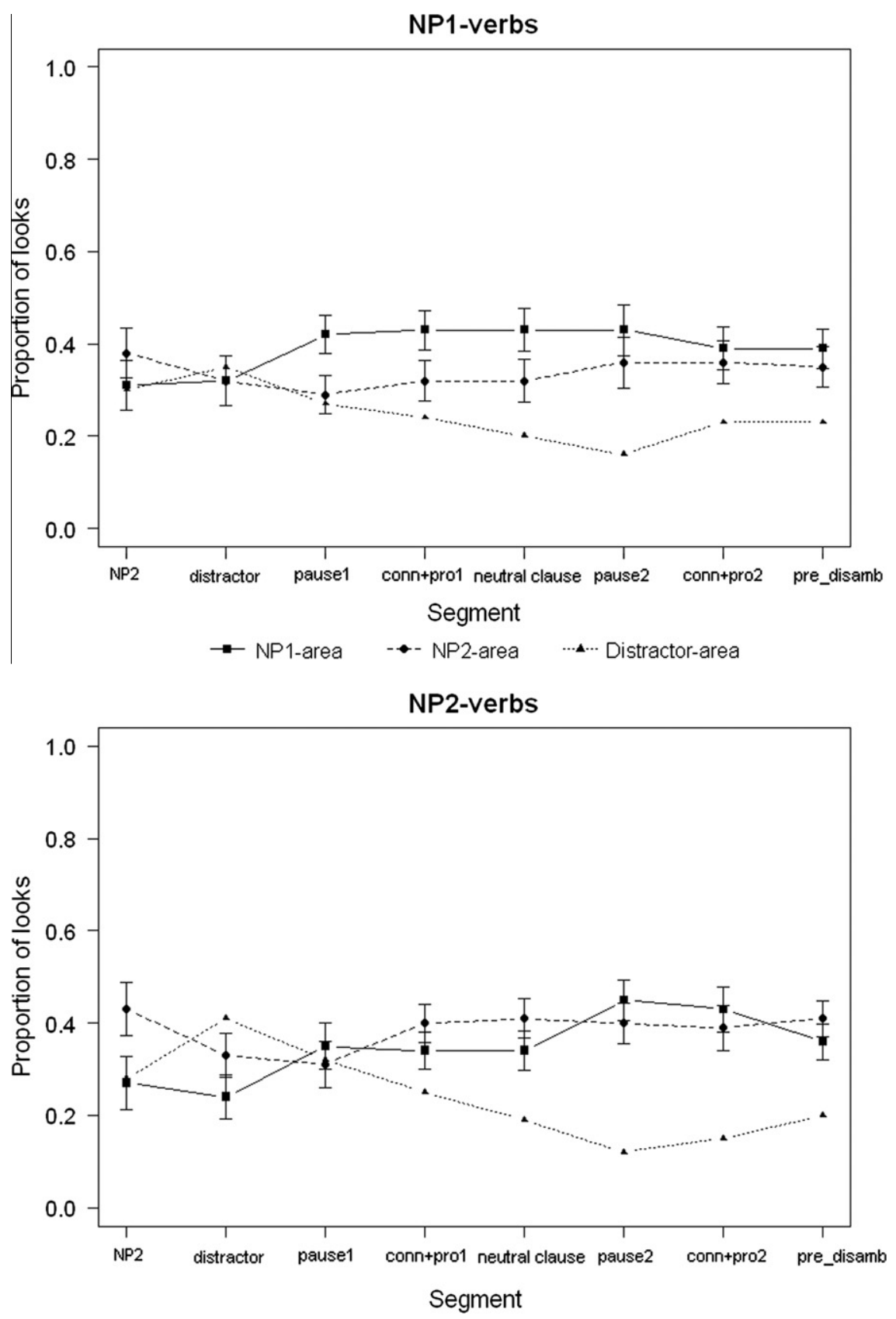

Fig. 3. Mean proportions of looks at the NP1-area, the NP2-area, and the Distractor-area in the NP1-verb condition (top) and the NP2-verb condition (bottom) for segments of analysis before the onset of the disambiguating word, and error bars indicating the standard error of the difference between the NP1-area and the NP2-area per segment (Experiment 1).

( $d=0.12 ; 95 \%$ CI $[0.02,0.22])$, whereas for NP2-verbs, the looks at the NP2-area and the NP1-area did not differ $(d=0.04 ; 95 \%$ CI $[-0.06,0.14])$. In the neutral segment, there was an interaction between NP-area and Verbbias, too. In the NP1-verb condition, participants looked significantly (by items marginally significantly) more at the NP1area than at the NP2-area $(d=0.11 ; 95 \% \mathrm{CI}[0.02,0.11])$. In the NP2-verb condition, however, participants did not look significantly more at the NP2-area than at the NP1-area $(d=0.07 ; 95 \% \mathrm{CI}[-0.02,0.16])$. Although an interaction was observed, it did not consist of two simple main effects, as expected on the basis of the focus hypothesis. This point will be addressed in the discussion.

Two further effects should be mentioned. In the NP2 segment, there was an effect of NP-area: Participants looked more at the NP2-area than at the NP1-area $(d=0.11 ; 95 \% \mathrm{CI}[0.02,0.20])$. In the distractor segment, this effect has disappeared. In the pause1 segment, an 
NP-area effect occurred: Participants looked more at the NP1-area than at the NP2-area ( $d=0.09 ; 95 \%$ $[0.02,0.11])$. There was no interaction between Verbbias and NP-area.

Segments of analysis after onset of the disambiguating word

When disambiguating information is presented to the participants, the pronoun can definitely be resolved. It is to be expected, therefore, that somewhere at or after the disambiguating information is perceived, the eye movements will be directed to the referent. Since the referent of the NP1-verbs in the congruent condition is the NP1protagonist and in the incongruent condition the NP2-protagonist, and since the situation is exactly the other way around for NP2-verbs, an interaction is predicted between Verbbias, NP-area, and Congruency. This interaction is predicted both by the focusing account and the integration account.

The process of pronoun resolution takes time and previous studies have shown that the resolution of incongruent sentences takes more time than the resolution of congruent sentences. As stated in the introduction, this congruency effect is in agreement with both the focusing account and the integration account. The present study, however, does not measure reading time. Instead, it measures what participants look at while they are resolving the pronoun. If the resolution of an incongruent sentence takes more time and participants need more time to determine the referent, they may start looking at that referent later than when the sentence has a congruent ending. The congruency effect, therefore, might be revealed by a difference in the moment participants start looking at the referent: They may start looking at the referent later in the incongruent sentences than in the congruent sentences. So, an interaction between Verbbias and NP-area is expected to occur in an earlier segment of the congruent sentences than of the incongruent sentences. Three segments were analyzed: the disambiguating word (disamb), the rest of the disambiguating clause (post_disamb), and the segment after the end of the sentence (post_sentence). The average proportion of looks at the NP1-area, the NP2area, and the distractor-area for the segments after the onset of the disambiguating word are plotted in Fig. 4, together with error bars representing the standard errors related to the difference between the proportions of looks at the NP1-area and the NP2-area. The results of the statistical analyses are displayed in Table 3. Only trials in which the correct referent had been chosen in the naming task were included. This resulted in the exclusion of $24 \%$ of the data: $17 \%$ in the NP1-verb congruent condition, $29 \%$ in the NP1-verb incongruent condition, $22 \%$ in the NP2verb congruent condition, and $28 \%$ in the NP2-verb incongruent condition. More errors were made in the incongruent than in the congruent condition (29\% versus $19 \% ; t(37)=2.37, p<.05)$.

Although the disamb segment contained the information that enabled the definite resolution of the pronoun, the analyses showed no effects in this segment. In the

Table 2

Results of the statistical analyses of the proportion of looks data for segments of analysis that started before the onset of the disambiguating word as a function of Verbbias (V) and NP-area (N). The table gives an overview of $F 1, F 2$, and MinF' analyses (only Fs $>1$; Experiment 1).

\begin{tabular}{|c|c|c|c|c|c|c|c|c|c|c|}
\hline \multirow[t]{2}{*}{ Segment of analysis } & & \multicolumn{3}{|c|}{ By participants } & \multicolumn{3}{|l|}{ By items } & \multicolumn{3}{|l|}{$\operatorname{Min} F^{\prime}$} \\
\hline & & $F 1(1,37)$ & MSE & $p$ & $F 2(1,14)$ & MSE & $p$ & $d f 2$ & $\operatorname{MinF}^{\prime}(1, d f 2)$ & $p$ \\
\hline \multirow[t]{3}{*}{ NP2 } & V & & & & & & & & & \\
\hline & $\mathrm{N}$ & 5.55 & 0.086 & $0.024^{*}$ & 32.75 & 0.003 & $0.000^{* *}$ & 18.9 & 4.75 & $0.042^{*}$ \\
\hline & $\mathrm{V} * \mathrm{~N}$ & 2.09 & 0.031 & 0.156 & 2.89 & 0.003 & 0.111 & 34.7 & 1.21 & 0.279 \\
\hline \multirow[t]{3}{*}{ Distractor } & $\mathrm{V}$ & 5.14 & 0.008 & $0.029^{*}$ & 4.05 & 0.002 & $0.064^{\mathrm{a}}$ & 44.8 & 2.27 & 0.139 \\
\hline & $\mathrm{N}$ & 1.35 & 0.061 & 0.253 & 3.01 & 0.006 & 0.105 & & & \\
\hline & $\mathrm{V} * \mathrm{~N}$ & 2.90 & 0.034 & $0.097^{\mathrm{a}}$ & 2.67 & 0.006 & 0.125 & 42.1 & 1.39 & 0.245 \\
\hline \multirow[t]{3}{*}{ Pause1 } & V & 2.75 & 0.007 & 0.106 & 1.11 & 0.004 & 0.309 & & & \\
\hline & $\mathrm{N}$ & 6.32 & 0.047 & $0.016^{*}$ & 9.09 & 0.007 & $0.009^{* *}$ & 34.0 & 3.73 & $0.062^{\mathrm{a}}$ \\
\hline & $\mathrm{V} * \mathrm{~N}$ & 2.31 & 0.035 & 0.137 & 1.97 & 0.007 & 0.182 & 43.5 & 1.06 & 0.309 \\
\hline \multirow[t]{3}{*}{ Conn + pro 1} & V & & & & & & & & & \\
\hline & $\mathrm{N}$ & & & & 2.97 & 0.005 & 0.107 & & & \\
\hline & $\mathrm{V} * \mathrm{~N}$ & 5.95 & 0.038 & $0.020^{*}$ & 9.25 & 0.005 & $0.009^{* *}$ & 32.7 & 3.62 & $0.066^{\mathrm{a}}$ \\
\hline \multirow[t]{3}{*}{ Neutral clause } & V & & & & & & & & & \\
\hline & $\mathrm{N}$ & & & & & & & & & \\
\hline & $\mathrm{V} * \mathrm{~N}$ & 10.61 & 0.027 & $0.002^{* *}$ & 6.71 & 0.008 & $0.021^{*}$ & 47.9 & 4.11 & $0.048^{*}$ \\
\hline \multirow[t]{3}{*}{ Pause2 } & V & 3.43 & 0.006 & $0.072^{\mathrm{a}}$ & 4.05 & 0.001 & $0.064^{\mathrm{a}}$ & 37.6 & 1.85 & 0.182 \\
\hline & $\mathrm{N}$ & 2.83 & 0.054 & 0.101 & 1.88 & 0.017 & 0.192 & 47.3 & 1.13 & 0.293 \\
\hline & $\mathrm{V} * \mathrm{~N}$ & & & & & & & & & \\
\hline Conn + pro2 & V & 5.02 & 0.007 & $0.031^{*}$ & 3.77 & 0.002 & $0.073^{\mathrm{a}}$ & 45.6 & 2.15 & 0.149 \\
\hline & $\mathrm{N}$ & & & & & & & & & \\
\hline & $\mathrm{V} * \mathrm{~N}$ & & & & & & & & & \\
\hline \multirow[t]{3}{*}{ Pre_disamb } & V & 1.37 & 0.006 & 0.250 & & & & & & \\
\hline & $\mathrm{N}$ & & & & & & & & & \\
\hline & $\mathrm{V} * \mathrm{~N}$ & 2.55 & 0.030 & 0.119 & & & & & & \\
\hline
\end{tabular}

\footnotetext{
${ }^{*} p<.05$

* $p<.01$.

a $p<.1$.
} 
post_disamb segment, there was a three-way interaction between Verbbias, NP-area, and Congruency. To further examine this interaction, separate analyses for the congruent and the incongruent conditions were performed. In the congruent condition, there was an interaction between Verbbias and NP-area: $F 1(1,36)=31.72, \quad M S E=0.111$, $p<.001 ; F 2(1,14)=23.39, M S E=0.024, p<.001$. Pairwise comparisons revealed that participants looked more at the NP1-area than at the NP2-area in the congruent NP1verb condition ( $d=0.26$; 95\% CI $[0.13,0.39])$, and more at the NP2-area than at the NP1-area in the congruent NP2verb condition $(d=0.36 ; 95 \% \mathrm{Cl}[0.22,0.50])$. In the incongruent condition, no interaction between Verbbias and NP-area was observed: $F 1(1,33)=2.70, M S E=0.122$, $p=.110 ; F 2(1,14)=4.61, M S E=0.026, p=.05$. Participants looked more at the NP2-area than at the NP1-area in the incongruent NP1-verb condition $(d=0.18 ; 95 \%$ $[0.04,0.32]$ ), however, this failed to be significant by items. Participants' looks at the NP1-area and the NP2-area did not differ in the NP2-verb incongruent condition $(d=0.01 ; 95 \% \mathrm{CI}[-0.14,0.16])$. These results give evidence for the congruency effect: In the congruent sentences, participants start looking at the referent earlier than in the incongruent sentences.

The three-way interaction showed up again in the post_sentence segment. To further examine this interaction, again separate analyses and pairwise comparisons were performed. In the congruent condition, the interaction between Verbbias and NP-area was significant: $F 1(1,36)=33.66, M S E=0.106, p<.001 ; F 2(1,14)=19.52$, $M S E=0.035, p<.01$. Participants looked more at the NP1area than at the NP2-area in the congruent NP1-verb condition ( $d=0.25 ; 95 \% \mathrm{CI}[0.10,0.40])$, but this was only significant by participants, and they looked more at the NP2-area than at the NP1-area in the congruent NP2-verb condition ( $d=0.38 ; 95 \% \mathrm{CI}[0.24,0.52])$. In the incongruent condition, the interaction between Verbbias and NP-area, this time, was significant as well: $F 1(1,33)=12.57$, $M S E=0.105, \quad p<.01 ; \quad F 2(1,14)=14.92, \quad M S E=0.032$, $p<.01$. Participants looked more often at the NP2-area
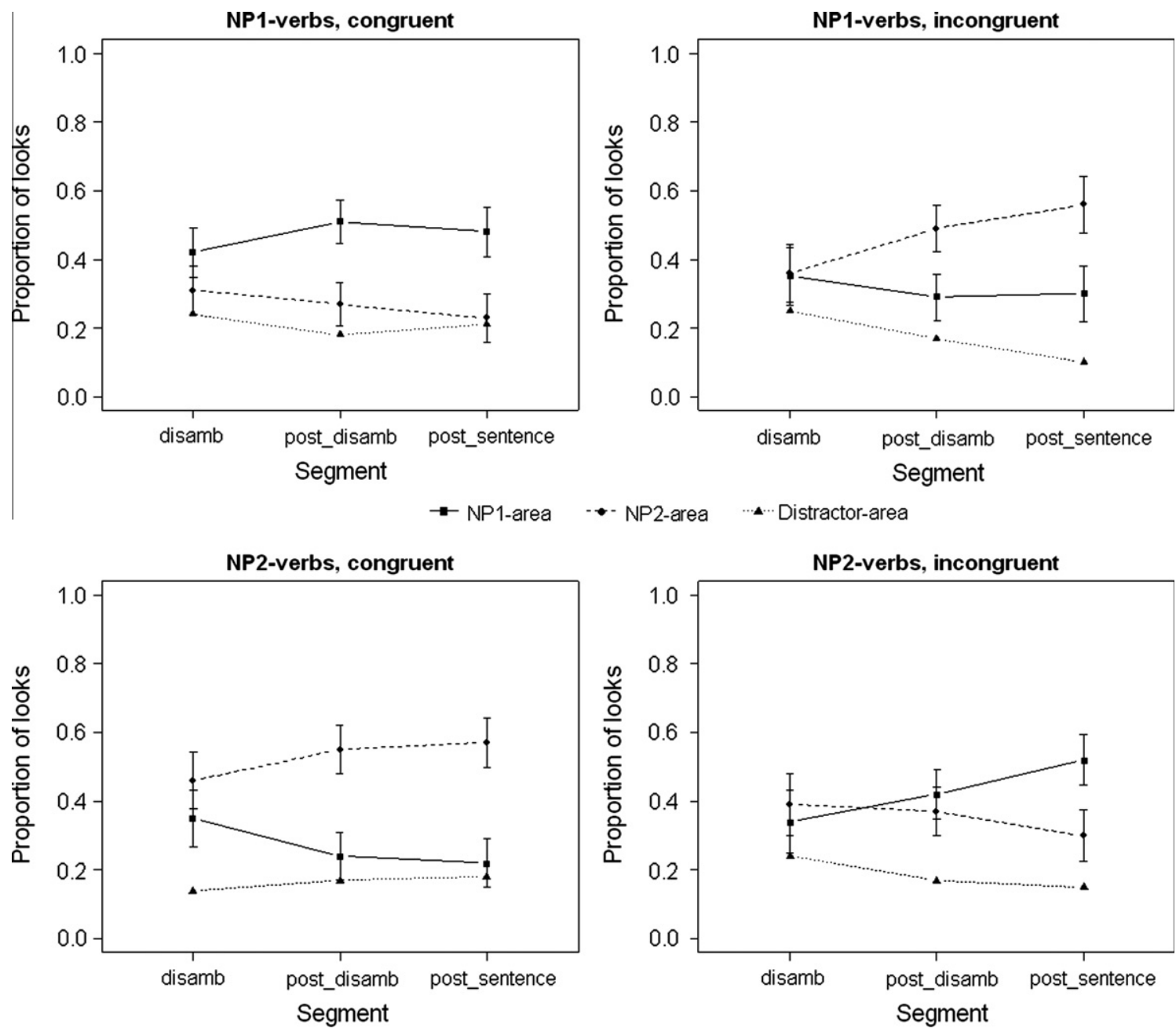

NP2-area $\quad \cdots$-...Distractor-area

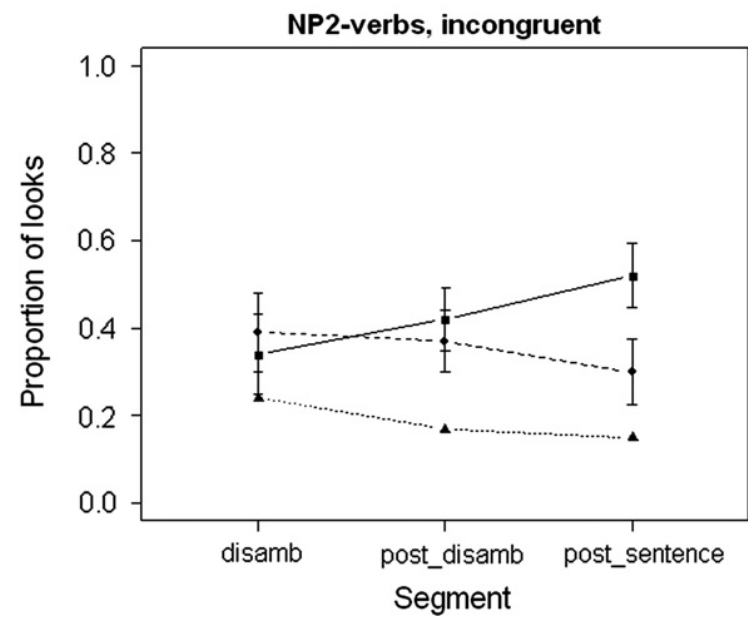

Fig. 4. Mean proportions of looks at the NP1-area, the NP2-area, and the Distractor-area in the NP1-verb congruent (top left), the NP1-verb incongruent (top right), the NP2-verb congruent (bottom left), and NP2-verb incongruent (bottom right) conditions for the segments of analysis after the onset of the disambiguating word, and error bars indicating the standard error of the difference between the NP1-area and the NP2-area per segment (Experiment 1). 
Table 3

Results of the statistical analyses of the proportion of looks data for segments of analysis that start after the onset of the disambiguating word as a function of Verbbias (V), NP-area (N), and Congruency (C). The table gives an overview of F1, F2, and MinF' analyses (only Fs > 1; Experiment 1 ).

\begin{tabular}{|c|c|c|c|c|c|c|c|c|c|c|}
\hline \multirow[t]{2}{*}{ Segment of analysis } & & \multicolumn{3}{|c|}{ By participants } & \multicolumn{3}{|l|}{ By items } & \multicolumn{3}{|l|}{$\operatorname{Min} F^{\prime}$} \\
\hline & & $F 1(1,33)$ & MSE & $p$ & $F 2(1,28)$ & MSE & $p$ & $d f 2$ & $\operatorname{MinF}^{\prime}(1, d f 2)$ & $p$ \\
\hline \multirow[t]{7}{*}{ Disamb } & $\mathrm{V}$ & & & & 2.31 & 0.004 & 0.140 & & & \\
\hline & $\mathrm{C}$ & 1.31 & 0.011 & 0.261 & 1.87 & 0.004 & 0.183 & & & \\
\hline & $\mathrm{N}$ & & & & & & & & & \\
\hline & $\mathrm{V}^{*} \mathrm{C}$ & 2.52 & 0.017 & 0.122 & 1.16 & 0.004 & 0.291 & & & \\
\hline & $\mathrm{V}^{*} \mathrm{~N}$ & 6.59 & 0.140 & $0.015^{*}$ & 2.17 & 0.029 & 0.152 & 51.7 & 1.63 & 0.207 \\
\hline & $\mathrm{C}^{*} \mathrm{~N}$ & & & & & & & & & \\
\hline & $\mathrm{V}^{*} \mathrm{C}^{*} \mathrm{~N}$ & & & & & & & & & \\
\hline \multirow[t]{7}{*}{ Post_disamb } & $\mathrm{V}$ & & & & & & & & & \\
\hline & $\mathrm{C}$ & 1.78 & 0.007 & 0.191 & & & & & & \\
\hline & $\mathrm{N}$ & 4.22 & 0.058 & $0.048^{*}$ & 1.48 & 0.025 & 0.234 & 52.6 & 1.10 & 0.299 \\
\hline & $\mathrm{V}^{*} \mathrm{C}$ & & & & & & & & & \\
\hline & $\mathrm{V}^{*} \mathrm{~N}$ & 6.16 & 0.113 & $0.018^{*}$ & 3.12 & 0.025 & $0.088^{\mathrm{a}}$ & 57.5 & 2.07 & 0.156 \\
\hline & $\mathrm{C}^{*} \mathrm{~N}$ & 1.11 & 0.048 & 0.299 & & & & & & \\
\hline & $\mathrm{V}^{*} \mathrm{C}^{*} \mathrm{~N}$ & 22.80 & 0.119 & $0.000^{* * *}$ & 23.87 & 0.025 & $0.000^{* *}$ & 60.3 & 11.66 & $0.001^{* *}$ \\
\hline \multirow[t]{7}{*}{ Post_sentence } & $\mathrm{V}$ & & & & & & & & & \\
\hline & $\mathrm{C}$ & 8.56 & 0.019 & $0.006^{* *}$ & 5.96 & 0.005 & $0.021^{*}$ & 60.4 & 3.51 & $0.066^{\mathrm{a}}$ \\
\hline & $\mathrm{N}$ & 1.17 & 0.083 & 0.286 & & & & & & \\
\hline & $\mathrm{V}^{*} \mathrm{C}$ & 1.81 & 0.014 & 0.188 & 2.86 & 0.005 & 0.102 & 55.7 & 1.11 & 0.297 \\
\hline & $\mathrm{V}^{*} \mathrm{~N}$ & 1.31 & 0.113 & 0.261 & & & & & & \\
\hline & $\mathrm{C}^{*} \mathrm{~N}$ & & & & & & & & & \\
\hline & $\mathrm{V}^{*} \mathrm{C}^{*} \mathrm{~N}$ & 40.96 & 0.098 & $0.000^{* *}$ & 34.36 & 0.034 & $0.000^{* *}$ & 61.0 & 18.69 & $0.000^{* *}$ \\
\hline
\end{tabular}

* $p<.05$.

** $p<.01$.

a $p<.1$.

than at the NP1-area in the incongruent NP1-verb condition $(d=0.22 ; 95 \% \mathrm{CI}[0.05,0.39])$, and they looked more often at the NP1-area than at the NP2-area in the NP2-verb incongruent condition ( $d=0.17 ; 95 \% \mathrm{CI}[0.02,0.32])$.

\section{Discussion}

The visual world paradigm is based on the phenomenon that eye movements are closely time-locked to linguistic processing when there is a direct meaningful link between a visual stimulus and an auditory linguistic stimulus. The present study evidenced this phenomenon in the results at the segment in which the second protagonist was mentioned. When the name of this protagonist in the main clause was pronounced, participants looked significantly more at the depiction of this protagonist than at that of the first-mentioned protagonist. Clearly, the eyes give away what the listener is processing. Right after this segment, when the sentence mentioned the distractor object, there was no longer a clear difference between the looks at the first and the second protagonist. The advantage of the second protagonist in the previous segment had disappeared.

In the next segment, the first pause segment, participants looked significantly more at the depiction of the first protagonist than at the depiction of the second protagonist, independent of verb type, indicating an influence of first mention. As explained in the introduction, the influence of several structure related factors, such as first mention, subject preference and parallel strategy, was confounded in the experiment and, therefore, no conclusion is possible with respect to which of these factors might have been responsible for the effect.
Evidence for the focusing hypothesis is obtained in the conn + pro1 segment and the neutral clause segment. In these segments, there is an interaction between the implicit causality bias of the verb and the protagonists' area: If the main clause contained an NP1-verb, participants' looks were directed more at the depiction of the NP1-protagonist than at the depiction of the NP2-protagonist, whereas no statistically significant difference was found if the main clause contained an NP2-verb. The fact that there is a simple main effect for the NP1-verbs but not for the NP2-verbs can be explained by the simultaneous occurrence of the effects of implicit causality and first mention. For the NP1verbs, both effects reinforce each other; for the NP2-verbs, the two effects cancel each other. Since implicit causality is effective in the conn + pro1 segment and in the neutral clause segment, which is before the disambiguating word, this result is evidence for the focusing hypothesis.

After the offset of the disambiguating word and before the end of the sentence, implicit causality also played a role. Participants looked more at the referent than at the non-referent both for the NP1-verbs and the NP2-verbs. Furthermore, this effect occurred sooner in the congruent than in the incongruent condition. As mentioned above, this finding is in line with the congruency effect. After the offset of the sentence, the effect of referent no longer differentiated between the congruent and the incongruent conditions. The difference between the congruent and incongruent conditions, as observed in the previous segment, had gone. The results indicated that the pronoun resolution process had been completed in all conditions in this segment.

Experiment 1 indicates at what point during sentence processing the implicit causality bias of the verb affects processing. The interaction between verb condition and 
noun area in the conn + pro1 segment, where there is no disambiguation yet, indicates the early effect of implicit causality. However, there are two characteristics of the experiment that might have induced strategic processing. First, it might be objected that the experimental set up elicited the strategy to pay special attention to the implicit causality bias information since the task in the experiment required participants to name the referent of the ambiguous pronoun in the second and third clause after the sentence was finished. But against this objection pleads that half of the sentences were incongruent which means that the implicit causality information was not useful in disambiguating the pronoun. Second, all sentences in the experiment had the same structure. This characteristic, too, might have caused participants to process the sentences in a strategic way. These properties of the experimental setup leave the question open whether people would display this behavior under circumstances where the attention is not directed to the resolution of ambiguous pronouns in the context of verbs expressing an implicit causality bias.

To meet these objections, Experiment 2 was conducted. In this experiment, participants' attention was not directed to pronoun resolution, but instead just to the comprehension of the sentences and to the verification of statements that tested comprehension.

\section{Experiment 2}

Experiment 2 was similar to Experiment 1, but there were two main differences. First, the task in Experiment 2 did not require participants to name the referent of the ambiguous pronoun. Instead, the participants had to verify simple statements that tested their comprehension of the sentences. Second, Experiment 2 included filler sentences that contained no implicit causality verbs and had no connectives or other connectives than because. The filler sentences directed the attention away from the structure of the experimental sentences. An additional difference concerned the experimental materials. In Experiment 1 effects of an implicit causality bias showed up really soon in the second clause, as early as the first connective and pronoun. Therefore, there was no reason to maintain a neutral clause in the sentences. Leaving out the neutral clauses in Experiment 2 had the advantage of allowing a larger selection of implicit causality verbs from the set of verbs that were examined in the materials studies.

The goal of Experiment 2 was to find out whether the results of Experiment 1 should be attributed to strategic processing. So the main question is whether the effect of implicit causality is observed again before any disambiguating information has been encountered. This would rule out strategic behavior as an explanation for the results of Experiment 1.

\section{Method}

\section{Participants}

Thirty-five students of the Radboud University Nijmegen participated in the experiment ( 26 women and nine men, mean age 22). None of the participants was involved in the earlier experiments and pre-tests. They were native speakers of Dutch and reported having normal hearing and normal or corrected to normal vision (two participants had lenses). Due to inaccuracies in measurement, the data of two participants could not be analyzed. The data of the remaining 33 participants were entered into the analyses.

\section{Materials}

The experimental materials were structurally the same as in Experiment 1, with the exception of the neutral clause which was omitted in Experiment 2. Of the initial set of 44 implicit causality verbs that were submitted to the materials studies as explained earlier, 36 were selected for Experiment 2, 18 NP1-verbs and 18 NP2-verbs (see Appendix A for a list of the experimental verbs). The sentence completion scores for these verbs were obtained in pre-test 1 of Experiment 1. The completions for the NP1-verbs were in 94\% of the cases NP1 continuations (range: 86-99\%) and for the NP2-verbs in $83 \%$ of the cases NP2 continuations (range: $70-100 \%$ ).

As in Experiment 1, the congruent and incongruent subordinate clauses were pre-tested following the procedure of pre-test 3 . The 36 sentence pairs were judged by 40 participants, students of Tilburg University. For NP1-verb congruent sentences, the intended referent for the pronoun (NP1) was chosen in $87 \%$ of the cases, with certainty score .91 and for NP1-verbs incongruent sentences, the intended referent (NP2) was chosen in $77 \%$ of the cases with certainty score .82. For NP2-verb congruent sentences, the intended referent (NP2) was chosen in $97 \%$ of the cases with certainty score .95 and for NP2-verb incongruent sentences, the intended referent (NP1) was chosen in $88 \%$ of the cases with certainty score .85 .

In addition to the 36 experimental sentence pairs, 64 filler sentences were constructed. The filler sentences equaled the experimental sentences in length and contained two protagonists, but no interpersonal verb and no pronoun, and had a connective other than because or no connective. There were 12 filler sentences with a coordinated NP, as in "The ant and the pig were very successful at the housing fair with a new kind of pressure cooker"; five with the temporal connective toen (when or as) in the first clause, as in "When the turtle opened another bottle of beer, the shark took a handful of chips and a cracker", and five with this connective in the second clause, as in "The panda was confined to bed with a fever for a week, when the butterfly came along with a fruit basket"; five with the connective terwijl (while) in the first clause, as in "While the hedgehog was on his way to school, the sheep once again decided to play hooky", and five with this connective in the second clause, as in "The mole washed the peeled potatoes under the tap, while the snail carefully read the recipe"; 10 with clauses coordinated by the connective en (and), as in "The penguin packed the suitcases and the lion took care of the train tickets and airplane tickets"; and finally, 22 without a connective, with a factive predicate, for instance "The crocodile did not keep the promise to the crab to quit smoking before New Year's Eve".

For $25 \%$ of the sentences, verification statements were made, 13 true and 12 false. There were nine statements about the experimental sentences (five true, four false) 
and 16 about the filler sentences (eight true, eight false). The statements for the experimental sentences did not require the ambiguous pronoun to be resolved. An example of a (false) statement for the experimental sentence(s) "The mouse scolded $_{\text {NP2-verb }}$ the camel at cleaning, because he left (found) stuff all over the room" is "The camel was very neat". An example of a (true) filler statement is "The butterfly was on a sick call" for the corresponding filler sentence mentioned above.

There were eight practice sentences of which five had a verification statement (three true, two false). Because of the increase in number of sentences, additional animal drawings were created and tested and additional distractor objects were created.

The preparation of auditory stimuli. The sentences were recorded in a similar fashion as in Experiment 1, with a different female, native Dutch, speaker. The 72 experimental sentences, 64 fillers, and eight practice sentences were recorded in nine blocks of 16 sentences, each consisting of the congruent and incongruent versions of four experimental items, and eight filler/practice sentences. All sentences were recorded twice.

The auditory experimental sentences were constructed from the tokens in exactly the same way as in Experiment 1. However, because the speaker in Experiment 2 had read aloud at a much higher rate than the speaker in Experiment 1, the pauses between the clauses in Experiment 2 were shorter than the $600 \mathrm{~ms}$ pauses (on average) in Experiment 1. Therefore, in all experimental sentences, and in 28 of the 64 filler sentences, the clausal pauses were standardized to a length of $600 \mathrm{~ms}$. The pauses consisted of noise taken from the pauses in the tokens.

In a separate session, the 25 verification statements in the experiment and the five practice statements were recorded. To make them stand out from the sentences, the statements were pronounced by a male speaker (native Dutch). It was made sure that the statements had the same loudness as the sentences.

The preparation of visual stimuli. The visual stimuli were constructed in the same way as in Experiment 1.

\section{Design}

Each of the 36 experimental items occurred in four conditions, depending on whether the disambiguating clause was congruent or incongruent and whether the NP1 protagonist was depicted at the bottom left position or the bottom right position in the visual stimulus. The resulting 144 experimental stimuli were presented in four lists of 36 stimuli, so that each implicit causality verb occurred once in each list. Each list contained nine stimuli in each of the four conditions. The 64 filler items were inserted into the lists of experimental items. The four conditions of the experimental items and the five types of filler items were distributed pseudo-randomly over the lists. In each list, the NP1-protagonist was displayed equally often on the left and on the right side of the visual stimuli, each animal protagonist occurred once or twice, either in the NP1 or in the NP2 condition, in an experimental sentence and four or three times in a filler sentence, each protagonist-animal occurred approximately an equal number of times as the first and second protagonist in the sentences, and the true and false verification statements were distributed pseudorandomly over the list. Participants were assigned randomly to one of the four lists.

\section{Procedure}

The procedure was the same as the procedure of Experiment 1 except for the task. Participants were instructed to listen carefully to the sentences and judge whether statements about some of those sentences were true or false. Participants were not told that their pupil sizes were measured. After the naming session of the animals, and a practice session with eight practice items, the experimental and filler sentences were presented in two blocks of 50 items, with a pause in between. The first block started with three filler items as warming-up trials and the second block with two filler items. The same calibration and recalibration procedures were performed as in Experiment 1. The calibration procedure was performed before the practice block and before each of the experimental blocks. The trial structure was also the same as in Experiment 1, except that the visual stimulus disappeared at the offset of the auditory stimulus and that $200 \mathrm{~ms}$ after the end of the sentence a verification statement was presented or the next trial was started. The verifications had to be made by pressing a left (no) and right (yes) button on a response panel. The experiment lasted approximately $45 \mathrm{~min}$.

\section{Analysis}

The eye-movement data were analyzed in the same way as in Experiment 1. The visual stimuli contained the same four areas of interest: the NP1-area, the NP2-area, the distractor-area, and the background area. As in Experiment 1 , the auditory stimuli were divided into consecutive segments of analysis. There were five segments before the disambiguating word: the second protagonist in the biasing clause (NP2), the distractor segment (distractor), the pause after the first clause (pause), the connective and the pronoun of the subordinate clause (conn + pro), and the remainder of the subordinate clause up to the disambiguating word (pre_disamb), and two segments from the disambiguating word onward (disamb and post_disamb). The $200 \mathrm{~ms}$ segment after the end of sentence was not analyzed in this experiment.

As in Experiment 1, $200 \mathrm{~ms}$ were added to the onsets and offsets of the segments of analysis. The lengths of the segments of analysis were calculated by the same averaging procedure as in Experiment 1 (see Appendix B).

\section{Results}

The same ANOVAs with repeated measures were performed as in Experiment 1.

Segments of analysis before the onset of the disambiguating word

The data for the conn + pro segment are presented Fig. 5. The graph shows the proportion of looks before, during, and after this segment, starting at approximately $800 \mathrm{~ms}$ before the onset of the segment (as indicated by 

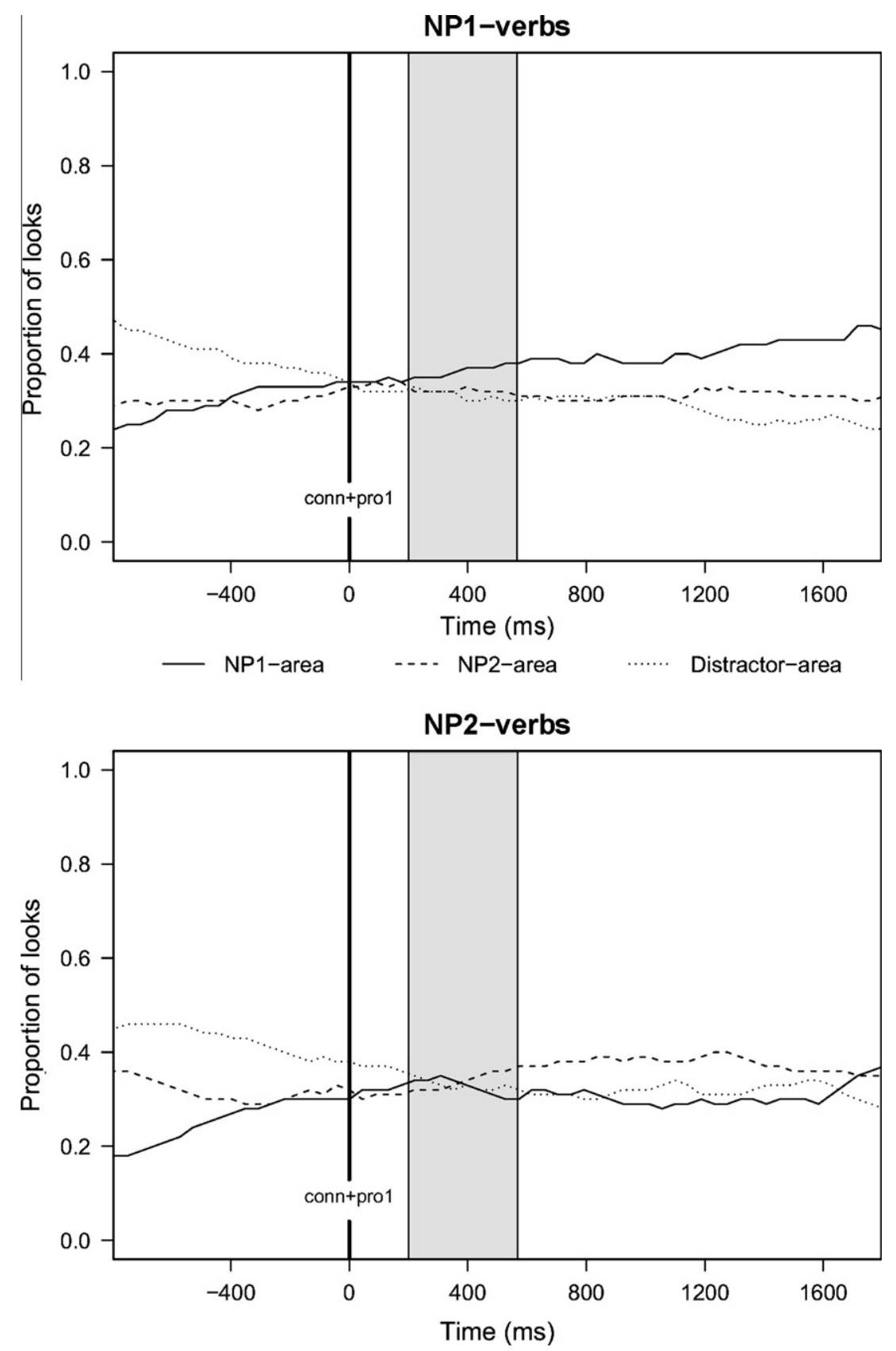

Fig. 5. Proportion of looks at the NP1-area, the NP2-area, and the Distractor-area in the NP1-verb (top) and the NP2-verb (bottom) conditions for the conn + pro segment of analysis (grey area) in Experiment 2. The data are aligned to the onset of the first connective.

the zero) and ending at $1700 \mathrm{~ms}$ after the onset of the segment. Visual inspection suggests that up to $400 \mathrm{~ms}$ before the onset, there are slightly more looks at the NP2-area than at the NP1-area. This difference disappears after this point, during the pause segment.

At the conn + pro segment, the proportions of looks at the NP1-area and the NP2-area start to diverge both for the NP1-area and the NP2-area: The looks at the NP1-area rise above those at the NP2-area for NP1-verbs, and the reverse happens for NP2-verbs. The differences between the looks at the two areas is apparent after the conn + pro segment, during the pre_disamb segment, well before any disambiguating information has been presented. The average proportions of looks at the NP1-area, the NP2-area, and the distractor-area for the segments before the disambiguating word are plotted in Fig. 6, together with error bars representing the standard errors related to the difference between the proportions of looks at the NP1-area and the NP2-area. The statistical tests are performed on the averages per segment (Table 4). 

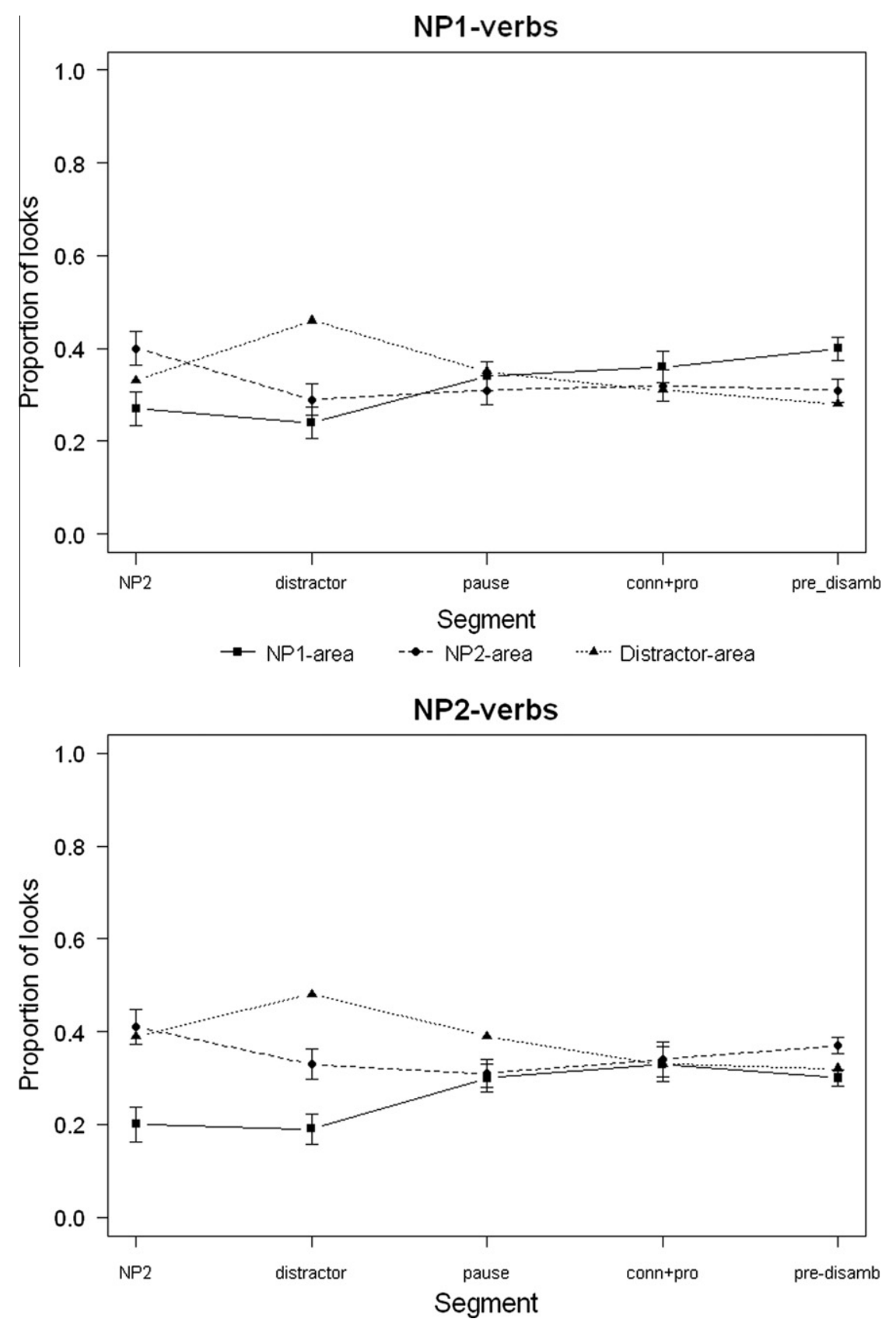

Fig. 6. Mean proportions of looks at the NP1-area, the NP2-area, and the Distractor-area in the NP1-verb condition (top) and the NP2-verb condition (bottom) for segments of analysis before the onset of the disambiguating word, and error bars indicating the standard error of the difference between the NP1-area and the NP2-area per segment (Experiment 2).

In the conn + pro segment, the interaction between NParea and Verbbias was not significant. However, in the pre_disamb segment, there was an interaction between Verbbias and NP-area: In the NP1-verb condition, there were significantly more looks at the NP1-area than at the NP2-area $(d=0.09$; 95\% CI $[0.04,0.14])$, whereas in the NP2-verb condition, there were significantly more looks at the NP2-area than at the NP1-area $(d=0.08 ; 95 \% \mathrm{CI}[0.05,0.11])$.

In the NP2 segment, there was an effect of NP-area: More looks were directed at the NP2-area than at the NP1-area $(d=0.17 ; 95 \% \mathrm{CI}[0.11,0.23])$, as in Experiment 1 . This result supports the sensitivity of the method. There also was an effect of NP-area in the distractor segment. There were more looks at the NP2-area than at the NP1-area $(d=0.10 ; 95 \%$ $\mathrm{CI}[0.04,0.16])$, but in the pause segment, well before the conn + pro segment, the number of looks at the NP1-area was the same as the number of looks at the NP2-area.

Segments of analysis after onset of the disambiguating word

Fig. 7 presents the means of the proportions of looks at the NP1-area, the NP2-area, and the distractor-area for the segments after the onset of the disambiguating word, 
Table 4

Results of the statistical analyses of the proportion of looks data for segments of analysis as a function of Verbbias (V), NP-area (N), and, from the disambiguating word onward, Congruency (C). The table gives an overview of $F 1, F 2$, and Min $F^{\prime}$ analyses (only $F$ 's > 1 ; Experiment 2 ).

\begin{tabular}{|c|c|c|c|c|c|c|c|c|c|c|}
\hline \multirow[t]{2}{*}{ Segment of analysis } & & \multicolumn{3}{|c|}{ By participants } & \multicolumn{3}{|l|}{ By items } & \multicolumn{3}{|c|}{$\operatorname{MinF}^{\prime}$} \\
\hline & & $F 1(1,32)$ & MSE & $p$ & $F 2(1,34)$ & MSE & $p$ & $d f 2$ & $\operatorname{MinF}^{\prime}(1, d f 2)$ & $p$ \\
\hline \multirow[t]{3}{*}{ NP2 } & $\mathrm{V}$ & 10.78 & 0.003 & $.002^{* *}$ & 5.24 & 0.003 & $.028^{*}$ & 60 & 3.53 & $.062^{\mathrm{a}}$ \\
\hline & $\mathrm{N}$ & 29.71 & 0.033 & $.000^{* * *}$ & 74.30 & 0.007 & $.000^{* *}$ & 54 & 21.22 & $.000^{* *}$ \\
\hline & $\mathrm{V}^{*} \mathrm{~N}$ & 4.19 & 0.010 & $.049^{*}$ & 3.28 & 0.007 & $.079^{a}$ & 65 & 1.84 & .176 \\
\hline \multirow[t]{3}{*}{ Distractor } & V & & & & & & & & & \\
\hline & $\mathrm{N}$ & 11.39 & 0.027 & $.002^{* *}$ & 23.19 & 0.007 & $.000^{* *}$ & 57 & 7.64 & $.008^{* *}$ \\
\hline & $\mathrm{V}^{*} \mathrm{~N}$ & 10.80 & 0.008 & $.002^{* *}$ & 5.06 & 0.007 & $.031^{*}$ & 59 & 3.45 & $.065^{\mathrm{a}}$ \\
\hline \multirow[t]{3}{*}{ Pause } & V & 3.07 & 0.005 & $.089^{\mathrm{a}}$ & 1.12 & 0.004 & .298 & & & \\
\hline & $\mathrm{N}$ & & & & & & & & & \\
\hline & $\mathrm{V}^{*} \mathrm{~N}$ & & & & & & & & & \\
\hline \multirow[t]{3}{*}{ Conn + pro } & $\mathrm{V}$ & 1.44 & 0.005 & .239 & & & & & & \\
\hline & $\mathrm{N}$ & & & & & & & & & \\
\hline & $\mathrm{V}^{*} \mathrm{~N}$ & 1.16 & 0.016 & .289 & 1.54 & 0.008 & .223 & & & \\
\hline \multirow[t]{3}{*}{ Pre_disamb } & $\mathrm{V}$ & 5.00 & 0.002 & $.032^{*}$ & 1.61 & 0.004 & .213 & 53 & 1.22 & .274 \\
\hline & $\mathrm{N}$ & & & & & & & & & \\
\hline & $\mathrm{V}^{*} \mathrm{~N}$ & 31.14 & 0.007 & $.000^{* *}$ & 16.77 & 0.007 & $.000^{* *}$ & 61 & 10.90 & $.002^{* *}$ \\
\hline \multirow[t]{7}{*}{ Disamb } & V & 4.59 & 0.006 & $.040^{*}$ & 2.09 & 0.006 & .153 & 99 & 1.44 & .234 \\
\hline & $\mathrm{C}$ & & & & & & & & & \\
\hline & $\mathrm{N}$ & & & & & & & & & \\
\hline & $\mathrm{V}^{*} \mathrm{C}$ & & & & & & & & & \\
\hline & $\mathrm{V}^{*} \mathrm{~N}$ & 1.19 & 0.044 & .283 & 2.00 & 0.023 & .162 & & & \\
\hline & $\mathrm{C}^{*} \mathrm{~N}$ & 1.90 & 0.036 & .177 & 1.52 & 0.023 & .222 & & & \\
\hline & $\mathrm{V}^{*} \mathrm{C}^{*} \mathrm{~N}$ & 1.90 & 0.025 & .177 & 1.07 & 0.023 & .304 & & & \\
\hline \multirow[t]{7}{*}{ Post_disamb } & V & 9.91 & 0.004 & $.004^{* *}$ & 3.32 & 0.005 & $.073^{\mathrm{a}}$ & 97 & 2.49 & .114 \\
\hline & $\mathrm{C}$ & & & & & & & & & \\
\hline & $\mathrm{N}$ & & & & & & & & & \\
\hline & $\mathrm{V}^{*} \mathrm{C}$ & & & & & & & & & \\
\hline & $\mathrm{V}^{*} \mathrm{~N}$ & & & & & & & & & \\
\hline & $\mathrm{C}^{*} \mathrm{~N}$ & & & & & & & & & \\
\hline & $\mathrm{V}^{*} \mathrm{C}^{*} \mathrm{~N}$ & 17.02 & 0.030 & $.000^{* *}$ & 18.60 & 0.014 & $.000^{* *}$ & 84 & 8.89 & $.004^{* *}$ \\
\hline
\end{tabular}

${ }^{*} p<.05$.

** $p<.01$.

a $p<.1$.

together with error bars representing the standard errors related to the difference between the proportions of looks at the NP1-area and the NP2-area. Table 4 (lower part) shows the corresponding statistics.

In the post_disamb segment, the three-way interaction between Verbbias, NP-area, and Congruency was significant, as in Experiment 1. In the NP1-verb congruent condition, there were more looks at the NP1-area than at the NP2-area $(d=0.11 ; 95 \%$ CI $[0.03,0.11])$; in the NP1-verb incongruent condition, the looks at the NP2-area and at the NP1-area did not differ significantly $(d=0.07 ; 95 \% \mathrm{CI}$ $[-0.03,0.17]$; in the NP2-verb congruent condition, the difference between looks at the NP2-area and the NP1area almost reached significance $(d=0.08 ; 95 \% \mathrm{CI}$ $[-0.008,0.168])$, and in the NP2-verb incongruent condition, there were more looks at the NP1-area than at and NP2-area $(d=0.10 ; 95 \%$ CI $[0.02,0.12])$.

\section{Discussion}

As in Experiment 1, the results of Experiment 2 showed an interaction between NP-area and Verbbias before any disambiguating information had been presented. This interaction in the pre_disamb segment consisted of two simple main effect: There were significantly more looks at the NP1-area than the NP2-area in the NP1-verb condition, and significantly more looks at the NP2-area than at the NP1-area in the NP2-verb condition. This result shows that there is an effect of the influence of the implicit causality bias of the verb early in the sentence, well before any disambiguating information was presented. Both Experiments 1 and 2 clearly support the focusing account of the influence of the implicit causality bias. Unlike in Experiment 1, no effect of first mention was found. This issue will be taken up in the general discussion.

The post_disamb segment revealed evidence of the pronoun resolution process in the three-way interaction effect. More looks were launched at the referent than at the non-referent of the pronoun in the NP1-verb congruent and the NP2-verb incongruent condition, indicating a slight dominance of the first-mentioned protagonist. In the NP1-verb incongruent and NP2-verb congruent conditions, the looks were directed more frequently at the referent than the non-referent, but, unlike in Experiment 1, the differences were not significant. This issue, too, will be discussed in the general discussion.

In Experiment 1, the interaction between the Verbbias and NP-area showed up as early as the segment with the 

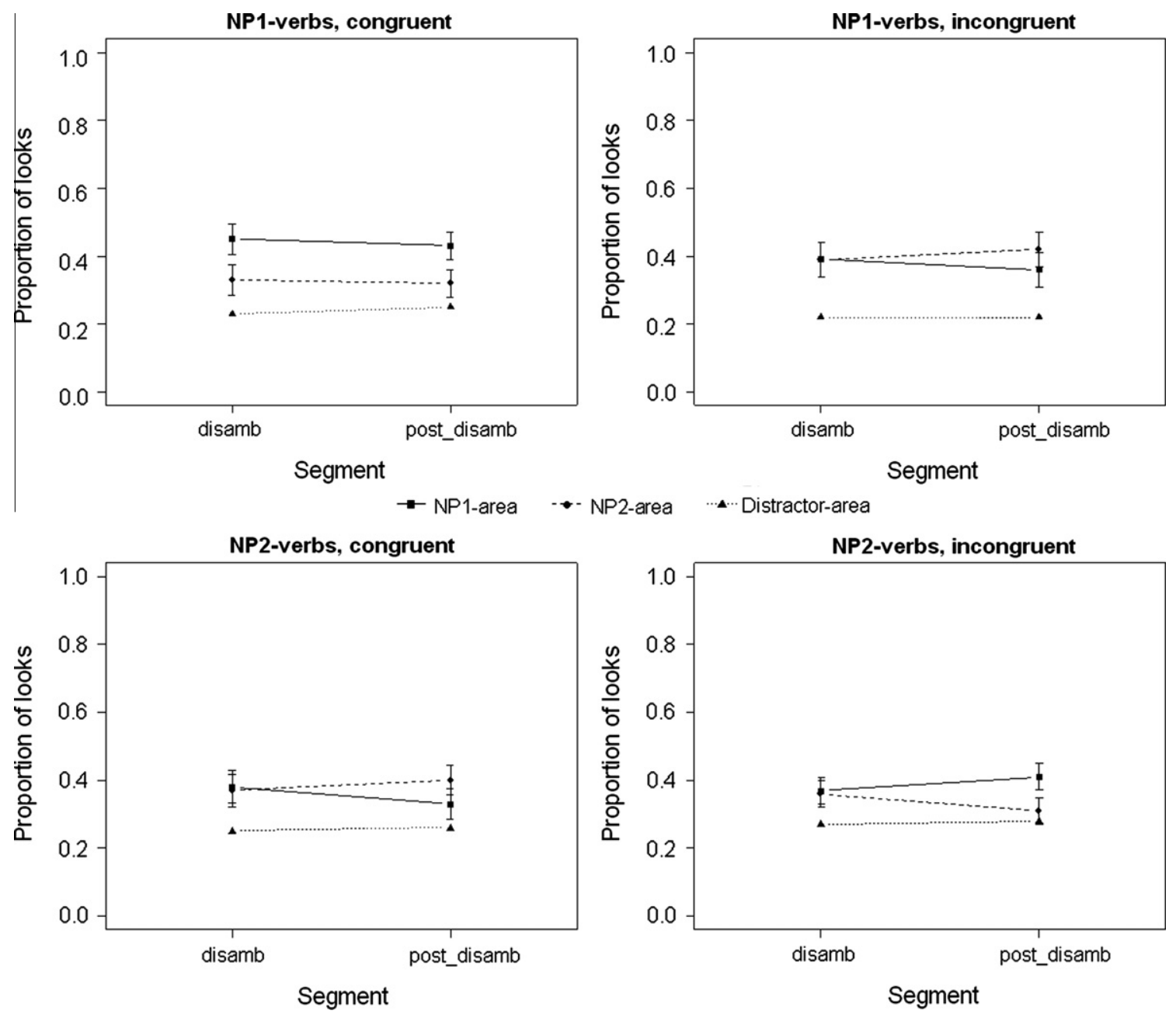

Fig. 7. Mean proportions of looks at the NP1-area, the NP2-area, and the Distractor-area in the NP1-verb congruent (top left), the NP1-verb incongruent (top right), the NP2-verb congruent (bottom left), and NP2-verb incongruent (bottom right) conditions for the segments of analysis after the onset of the disambiguating word, and error bars indicating the standard error of the difference between the NP1-area and the NP2-area per segment (Experiment 2).

connective and the ambiguous pronoun, but in Experiment 2 , the effect appeared in the pre_disamb segment, that is after the ambiguous pronoun. A possible explanation can be given why the interaction effect occurs in a later segment in Experiment 2 than in Experiment 1. The rate of speaking in Experiment 2 was faster than in Experiment 1 (see Appendix B). It is possible that the listener needs a certain time to process the implicit causality information. The effect occurred in Experiment 2 in the interval from 200 to $1100 \mathrm{~ms}$ after the offset of the connective and pronoun segment. If we apply the same time window in which we find the crossover interaction to the data of Experiment 1 , it turns out that the same crossover interaction is observed: The interaction between NP-area and Verb-condition consists of two significant simple main effects: for NP1-verbs, more looks at NP1-area than at NP2-area: $d=0.11 ; 95 \%$ CI $[0.01,0.20]$; for NP2-verbs, more looks at NP2-area than at NP1-area (one-sided): $d=0.07 ; 90 \% \mathrm{CI}$
$[-0.15,-0.001]$. Thus, in Experiment 1 the implicit causality bias is found for the NP2-verbs as well. Both experiments clearly evidenced an effect of the implicit causality verb bias well before any disambiguating information was obtained.

Experiments 1 and 2 differed in two important respects: the task and the materials. First, in Experiment 1 , participants were required to name the referent of the ambiguous pronoun. Their attention was, therefore, directed toward the resolution of the pronoun. In Experiment 2 , on the other hand, participants had to judge verification statements about the sentences. This task in no way focused on the resolution of the pronoun. Second, all sentences in Experiment 1 contained implicit causality verbs and ambiguous pronouns. This might have led the participants to strategically use the implicit causality information during the processing of the sentences, although half of the sentences turned out in the 
end to be inconsistent with this information. In Experiment 2 , only $36 \%$ of the sentences contained an implicit causality verb and an ambiguous pronoun, and, again, half of these sentences were in the end incongruent with the implicit causality information. All other sentences had different verbs and structures and did not contain ambiguous pronouns. Thus, the results of Experiment 2 rule out strategic processing as an explanation for the early effect of the implicit causality bias found in Experiment 1.

The implications of the findings of the two experiments for theories of the time course of the use of information sources, such as implicit causality information, are discussed below.

\section{General discussion}

Previous studies have established that both the firstmentioned noun phrase (Gernsbacher, 1990) and the subject (Gordon et al., 1993; Sheldon, 1974) receive special attention in language processing. The results of Experiment 1 are in line with these findings. In the pause right after the main clause and before the onset of the causal connective, the participants directed their eyes to the depiction of the first-mentioned protagonist in the main clause, regardless of the implicit causality bias. The firstmentioned protagonists in the main clauses were always also the clause subjects, leaving the question open which factor was responsible for the effect. Given that both factors contribute to the effect independently (Järvikivi et al., 2005), probably both played a role.

Experiment 2 did not show an effect of these structure related factors. There was no clear advantage of the firstmentioned (subject) protagonist over the second-mentioned (object) protagonist early in the second clause. A possible explanation for the absence of this effect might be that Experiment 2 presented sentences with all kinds of different sentence structures. In Experiment 1, all items were structurally identical and contained the ambiguous pronoun. This may have created clear structural expectancies about the type of sentence at the next trial and may have strengthened the role of structural factors in determining the referent of the pronoun, whereas in Experiment 2, participants had no idea in advance what type of sentence to expect at the next trial. This may have undermined any strategy related to structural factors.

The results of the experiments shed light on the main issue, raised in the introduction, at what moment during sentence processing implicit causality information comes into effect. Two views were distinguished with respect to this issue: the focusing account and the integration account. As explained in the introduction, thus far, empirical evidence in the literature for either of these accounts remained inconclusive (Garnham et al., 1996; Koornneef \& Van Berkum, 2006; Long \& De Ley, 2000; McDonald \& MacWhinney, 1995; Stewart et al., 2000). The inconclusiveness in the literature is partly due to the fact that the studies used unambiguous pronouns, because implicit causality effects during the processing of unambiguous pronouns may not be taken as evidence for the focusing account (Garnham, 2001). Therefore, the present study used ambiguous pronouns. In both experiments, interactions were found between the implicit causality verb bias and the protagonists' area before any disambiguating information had been given. The interaction was observed in Experiment 2 during the pre_disamb segment. In Experiment 1, in which the speaking rate was lower, the interaction was found already in an earlier segment, the conn + pro1 segment, and, as explained earlier, the effect of implicit causality occurred simultaneously with the effect of first mention. In both experiments it was observed in a segment preceding the disambiguating information that there were more looks at the NP1-area than at the NP2 areas for NP1-verbs and more looks at the NP2-area than at the NP1-area for NP2-verbs, supporting the focusing account.

The results of both experiments support the focusing account and present a problem to the integration account of the influence of the implicit causality bias. The integration account cannot explain an effect of implicit causality at or after the pronoun before disambiguation, since the pronoun contained no disambiguating information. Besides, the effect of implicit causality cannot be attributed to a strategy that capitalizes on the fact that the majority of the sentences in the experiment are congruent (cf. Garnham, 2001), since there were as many congruent as incongruent sentences in both experiments. It can be concluded, therefore, that, in line with the focusing account, implicit causality information is used early during processing, before disambiguating information is obtained. The results of the two experiments are in line with a recent study by Pyykkonen and Järvikivi (2010). They, too, used the visual world paradigm to investigate the influence of an implicit causality bias on sentence processing. They found a very early effect of the implicit causality bias, even before the connective. However, they did not include incongruent sentences in their experiment, and their finding, therefore, may be explained by a strategy on the part of the participants to capitalize on the implicit causality bias information, since it always led to the interpretation that is favored by the verb bias (Garnham, 2001). Moreover, their results cannot be generalized to incongruent sentences.

According to Garnham et al. (1996), focusing effects may be visible as early as the end of the main clause that contains the implicit causality verb (or even before that). However, at the end of the main clause no implicit causality effect was found. At this point, only first mention played a role in Experiment 1. Implicit causality came into effect at the first connective and pronoun segment, which raises the question whether the effect depends on the presence of the connective as well. Pyykkonen and Järvikivi (2010) found an effect before the conjunction, but as explained above, their results can be attributed to strategic processing which prevents a conclusion about the time course of implicit causality. The question is still open to debate. On the one hand, studies by Majid, Sanford, and Pickering (2007) support the idea that the main clause in itself is sufficient to invoke the implicit causality bias. They showed 
that participants indeed tended to continue fragments like 'John thwarted Pete' by providing a cause for the event, and that participants were biased to attribute the cause to the same protagonist as in fragments with a connective, like 'John thwarted Pete, because he'. Other studies, on the other hand, indicate that explicit cues about an upcoming cause, like the connective 'because', play an important role in invoking the implicit causality bias (Ehrlich, 1980, 1983; McKoon, Green, \& Ratcliff, 1993). The present study cannot elucidate on this question, since the presence of the connective was not manipulated.

In both experiments, the end of the sentence contained world knowledge information that disambiguated the implicit causality bias to a congruent or an incongruent reading. On the basis of the disambiguating information, the pronoun in the sentence could be resolved to either the first or the second protagonist. Several studies using reading time measures have shown that the disambiguation process takes more time for incongruent than for congruent sentences (Garnham, Oakhill, \& Cruttenden, 1992; Koornneef \& Van Berkum, 2006; Stewart et al., 2000; Vonk, 1985). This congruency effect shows that implicit causality contributes to the process of integrating the explicit disambiguating information with the previous discourse. The results of Experiment 1 corroborated this conjecture. After the disambiguating word but before the end of the sentence, participants fixated the referent more often than the non-referent in the congruent condition but not in the incongruent condition. After the end of the sentence, this difference had disappeared, suggesting that the referent had been chosen in all cases. Pairwise comparisons at this point revealed, furthermore, that the congruency effect was mainly concentrated in the incongruent condition, which makes sense considering that participants already looked more at the referent than the non-referent in the congruent condition before the end of the sentence. Experiment 2, on the other hand, did not provide clear evidence of a congruency effect at the end of the sentence. More looks were found at the referent than at the non-referent in the segment after disambiguation, but this effect was weaker than in Experiment 1 and occurred in the congruent and incongruent conditions at the same moment in time.

The different results may have been caused by the difference in tasks between the two experiments. In Experiment 1 , participants were instructed to verbally name the referent of the pronoun. This may have led them to look consistently at the referent at the end of the sentence and beyond, and a congruency effect emerged. In Experiment 2, participants were not concerned with the resolution of the pronoun at the end of the sentence. They expected a comprehension question, and while their looks were directed involuntarily at the referent protagonist in a lot of the cases nevertheless, in other cases they simply may have looked away or at the wrong protagonist, so no systematic congruency effect showed up.

In sum, the study shows that implicit causality information is used early during sentence processing and that it immediately contributes to the comprehension process, thus supporting the focusing account of the time course of the use of implicit causality information. The influence of implicit causality has been found at a moment during processing when no definitive integration was possible. The findings underscore that language processing is incremental and immediate.

\section{Acknowledgments}

We are indebted to Karien Coppens and Miekske van der Sman for their contributions to preparing the materials and conducting the experiments. We thank the editors and the anonymous reviewers for their helpful comments.

\section{Appendix A}

The 8 NP1-verbs and 8 NP2-verbs that were used in Experiment 1, and the 18 NP1-verbs and 18 NP2-verbs used in Experiment 2. The numbers indicate the experiments.

\begin{tabular}{|c|c|}
\hline NP1-verbs & NP2-verbs \\
\hline $\begin{array}{l}\text { afluisteren; } 1,2 \\
\quad \text { (to eavesdrop) }\end{array}$ & $\begin{array}{l}\text { aanklagen; } 1,2 \\
\text { (to sue) }\end{array}$ \\
\hline $\begin{array}{l}\text { beangstigen; } 1,2 \\
\quad \text { (to frighten) }\end{array}$ & $\begin{array}{l}\text { bekritiseren; } 2 \\
\text { (to criticize) }\end{array}$ \\
\hline $\begin{array}{l}\text { boos maken; } 2 \\
\text { (to anger) }\end{array}$ & $\begin{array}{l}\text { corrigeren; } 2 \\
\text { (to correct) }\end{array}$ \\
\hline $\begin{array}{l}\text { dwarsbomen; } 1,2 \\
\text { (to thwart) }\end{array}$ & $\begin{array}{l}\text { geloven; } 1,2 \\
\text { (to believe) }\end{array}$ \\
\hline $\begin{array}{l}\text { ergeren; } 2 \\
\quad \text { (to annoy) }\end{array}$ & $\begin{array}{l}\text { haten; } 1,2 \\
\text { (to hate) }\end{array}$ \\
\hline $\begin{array}{l}\text { imponeren; } 2 \\
\text { (to impress) }\end{array}$ & $\begin{array}{l}\text { medelijden hebben met; } 1,2 \\
\text { (to feel sorry for) }\end{array}$ \\
\hline $\begin{array}{l}\text { inspireren; } 2 \\
\quad \text { (to inspire) }\end{array}$ & $\begin{array}{l}\text { mopperen op; } 2 \\
\text { (to complain about) }\end{array}$ \\
\hline $\begin{array}{r}\text { irriteren; } 1,2 \\
\quad \text { (to irritate) }\end{array}$ & $\begin{array}{l}\text { ontslaan; } 1,2 \\
\text { (to fire) }\end{array}$ \\
\hline $\begin{array}{l}\text { krenken; } 2 \\
\quad \text { (to offend) }\end{array}$ & $\begin{array}{l}\text { opmerken; } 2 \\
\text { (to notice) }\end{array}$ \\
\hline $\begin{array}{l}\text { mislopen; } 1,2 \\
\quad \text { (to miss) }\end{array}$ & $\begin{array}{l}\text { schorsen; } 2 \\
\text { (to suspend) }\end{array}$ \\
\hline $\begin{array}{l}\text { ontmoedigen; } 1,2 \\
\text { (to discourage) }\end{array}$ & $\begin{array}{l}\text { twijfelen aan; } 1,2 \\
\text { (to doubt) }\end{array}$ \\
\hline $\begin{array}{l}\text { provoceren; } 2 \\
\quad \text { (to provoke) }\end{array}$ & $\begin{array}{l}\text { verachten; } 2 \\
\text { (to despise) }\end{array}$ \\
\hline $\begin{array}{l}\text { teleurstellen; } 2 \\
\quad \text { (to disappoint) }\end{array}$ & $\begin{array}{l}\text { verdenken; } 1,2 \\
\text { (to suspect) }\end{array}$ \\
\hline $\begin{array}{l}\text { verbazen; } 2 \\
\quad \text { (to astonish) }\end{array}$ & $\begin{array}{l}\text { vertrouwen; } 2 \\
\text { (to trust) }\end{array}$ \\
\hline $\begin{array}{l}\text { verontrusten; } 1 \\
\quad \text { (to upset) }\end{array}$ & $\begin{array}{l}\text { vervangen; } 2 \\
\text { (to replace) }\end{array}$ \\
\hline $\begin{array}{l}\text { verslaan; } 1,2 \\
\quad \text { (to beat) }\end{array}$ & $\begin{array}{l}\text { wantrouwen; } 1,2 \\
\text { (to distrust) }\end{array}$ \\
\hline $\begin{array}{l}\text { vervelen; } 2 \\
\text { (to bore) }\end{array}$ & $\begin{array}{l}\text { vrezen; } 2 \\
\text { (to fear) }\end{array}$ \\
\hline $\begin{array}{l}\text { wenken; } 2 \\
\quad \text { (to beckon) }\end{array}$ & $\begin{array}{l}\text { zorgen maken; } 2 \\
\text { (to worry) }\end{array}$ \\
\hline $\begin{array}{l}\text { winnen van; } 2 \\
\text { (to defeat) }\end{array}$ & \\
\hline
\end{tabular}




\section{Appendix B}

The average length (in ms) and the standard deviation (in brackets) of the segments of analysis that start before the onset of the disambiguating word in Experiments 1 and 2 .

\begin{tabular}{llll}
\hline Segment & $\begin{array}{l}\text { Verb- } \\
\text { bias }\end{array}$ & $\begin{array}{l}\text { Experiment } \\
1\end{array}$ & $\begin{array}{l}\text { Experiment } \\
2\end{array}$ \\
\hline NP2 & NP1 & $782(153)$ & $726(227)$ \\
& NP2 & $748(133)$ & $669(152)$ \\
Distractor & NP1 & $591(135)$ & $692(216)$ \\
& NP2 & $585(153)$ & $686(236)$ \\
Pause1 & NP1 & $635(135)$ & $600^{\mathrm{a}}(2)$ \\
& NP2 & $572(115)$ & $601^{\mathrm{a}}(5)$ \\
Con + pro1 & NP1 & $433(29)$ & $366(35)$ \\
& NP2 & $420(41)$ & $368(28)$ \\
Neutral & NP1 & $950(225)$ & - \\
& NP2 & $982(194)$ & - \\
Pause2 & NP1 & $511(96)$ & - \\
& NP2 & $537(105$ & - \\
Con + pro2 & NP1 & $435(31)$ & - \\
& NP2 & $416(37)$ & - \\
Pre_disamb & NP1 & $562(411)$ & $1121(324)$ \\
& NP2 & $1205(254)$ & $1146(272)$ \\
\hline
\end{tabular}

${ }^{\text {a }}$ Lengths were adjusted (see text).

The average length (in $\mathrm{ms}$ ) and the standard deviations (in brackets) of the segments of analysis that start after the onset of the disambiguating word, for NP1-bias and NP2bias congruent and incongruent items in Experiments 1 and 2.

\begin{tabular}{lllll}
\hline Segment & \multicolumn{4}{l}{ Verb- Congruency Experiment Experiment } \\
& bias & & 1 & 2 \\
\hline Disamb & NP1 & CON & $483(161)$ & $428(162)$ \\
& & INC & $446(134)$ & $410(146)$ \\
& NP2 & CON & $362(116)$ & $402(131)$ \\
& & INC & $409(145)$ & $462(156)$ \\
Post_disamb & NP1 & CON & $1003(244)$ & $895(168)$ \\
& & INC & $1011(266)$ & $904(164)$ \\
& NP2 & CON & $874(81)$ & $773(141)$ \\
& & INC & $866(95)$ & $759(145)$ \\
Post_sentence NP1 & CON & $484(63)$ & $200(0)$ \\
& & INC & $494(35)$ & $200(0)$ \\
& NP2 & CON & $496(21)$ & $200(0)$ \\
& & INC & $492(49)$ & $200(0)$ \\
\hline
\end{tabular}

\section{Supplementary material}

Supplementary data associated with this article can be found, in the online version, at doi:10.1016/j.jml.2011. 01.001 .

\section{References}

Altmann, G. T. M., \& Kamide, Y. (2004). Now you see it, now you don't: Mediating the mapping between language and the visual world. In J. M. Henderson \& F. Ferreira (Eds.), The interface of language, vision and action: Eye movements and the visual world (pp. 347-386). New York: Psychology Press.

Bird, K. D. (2002). Confidence intervals for effect sizes in analysis of variance. Educational and Psychological Measurement, 62, 197-226.

Boersma, P. (2001). Praat, a system for doing phonetics by computer. Glot International, 5, 341-345.

Caramazza, A., Grober, E., Garvey, C., \& Yates, J. (1977). Comprehension of anaphoric pronouns. Journal of Verbal Learning and Verbal Behavior, 16, 601-609.

Clark, H. H. (1973). The language-as-fixed-effect fallacy: A critique of language statistics in psychological research. Journal of Verbal Learning and Verbal Behavior, 12, 335-359.

Cooper, R. M. (1974). The control of eye fixation by the meaning of spoken language: A new methodology for the real-time investigation of speech perception. Cognitive Psychology, 6, 84-107.

Corrigan, R. (1993). Causal attributions to states and events described by different classes of verbs. British Journal of Social Psychology, 32, 335-348.

Corrigan, R. (2001). Implicit causality in language: Event participants and their interactions. Journal of Language and Social Psychology, 20, $285-320$

Cozijn, R. (2006). Het gebruik van oogbewegingen in leesonderzoek [The use of eye movements in reading research]. Tijdschrift voor Taalbeheersing, 28, 220-232.

Dahan, D., \& Tanenhaus, M. K. (2004). Continuous mapping from sound to meaning in spoken-language comprehension: Immediate effects of verb-based thematic constraints. Journal of Experimental Psychology: Learning, Memory, and Cognition, 30, 498-513.

Ehrlich, K. (1980). Comprehension of pronouns. The Quarterly Journal of Experimental Psychology, 32, 247-255.

Ehrlich, K. (1983). Eye movements in pronoun assignment: A study of sentence integration. In K. Rayner (Ed.), Eye movements in reading: Perceptual and language processes (pp. 253-268). New York: Academic Press.

Featherstone, C., \& Sturt, P. (2010). Because there was cause for concern: An investigation into the word-specific prediction account of the implicit causality effect. Quarterly Journal of Experimental Psychology, 63, 3-15.

Garnham, A. (2001). Mental models and the interpretation of anaphora. Hove: Psychology Press.

Garnham, A., Oakhill, J., \& Cruttenden, H. (1992). The role of implicit causality and gender cue in the interpretation of pronouns. Language and Cognitive Processes, 7, 231-255.

Garnham, A., Traxler, M. J., Oakhill, J., \& Gernsbacher, M. A. (1996). The locus of implicit causality effects in comprehension. Journal of Memory and Language, 35, 517-543.

Garvey, C., \& Caramazza, A. (1974). Implicit causality in verbs. Linguistic Inquiry, 4-5, 459-464.

Garvey, C., Caramazza, A., \& Yates, J. (1974-1975). Factors influencing assignment of pronoun antecedents. Cognition, 3, 227-243.

Gernsbacher, M. A. (1990). Language comprehension as structure building. Hillsdale, NJ: Lawrence Erlbaum.

Gordon, P. C., Grosz, B. J., \& Gilliom, L. A. (1993). Pronouns, names, and the centering of attention in discourse. Cognitive Science, 17, 311-347.

Gordon, P. C., Hendrick, R., \& Foster, K. L. (2000). Language comprehension and probe-list memory. Journal of Experimental Psychology: Learning Memory, and Cognition, 26, 766-775.

Greene, S. B., \& McKoon, G. (1995). Telling something we can't know: Experimental approaches to verbs exhibiting implicit causality Psychological Science, 6, 262-270.

Hobbs, J. R. (1979). Coherence and coreference. Cognitive Science, 3, 67-90.

Irwin, D. E. (2004). Fixation location and fixation duration as indices of cognitive processing. In J. M. Henderson \& F. Ferreira (Eds.), The interface of language, vision and action: Eye movements and the visual world (pp. 105-134). New York: Psychology Press.

Järvikivi, J., Van Gompel, R. G. P., Hyönä, J., \& Bertram, R. (2005). Pronominal resolution in Finnish: The impact of subjecthood and word order. Psychological Science, 16, 260-264.

Koornneef, A. W., \& Van Berkum, J. J. A. (2006). On the use of verb-based implicit causality in sentence comprehension: Evidence from self-paced reading and eye tracking. Journal of Memory and Language, 54, 445-465.

Long, D. L., \& De Ley, L. (2000). Implicit causality and discourse focus: The interaction of text and reader characteristics in pronoun resolution. Journal of Memory and Language, 42, 545-570.

Majid, A., Sanford, A. J., \& Pickering, M. J. (2007). The linguistic description of minimal social scenarios affects the extent of causal inference making. Journal of Experimental Social Psychology, 43, 918-932.

Masson, M. E. J., \& Loftus, G. R. (2003). Using confidence intervals for graphically based data interpretation. Journal of Experimental Psychology, 57(3), 203-220. 
McDonald, M. C., \& MacWhinney, B. J. (1995). The time course of anaphor resolution: Effects of implicit verb causality and gender. Journal of Memory and Language, 34, 543-566.

McKoon, G., Green, S. B., \& Ratcliff, R. (1993). Discourse models, pronoun resolution, and the implicit causality of verbs. Journal of Experimental Psychology: Learning, Memory, and Cognition, 19, 1-13.

Pyykkonen, P., \& Järvikivi, J. (2010). Activation and persistence of implicit causality information in spoken language comprehension. Experimental Psychology, 57, 5-16.

Rudolph, U., \& Försterling, F. (1997). The psychological causality implicit in verbs: A review. Psychological Bulletin, 121, 192-218.

Sheldon, A. (1974). Role of parallel function in acquisition of relative clauses in English. Journal of Verbal Learning and Verbal Behavior, 13, $272-281$.

Stevenson, R., Knott, A., Oberlander, J., \& McDonald, S. (2000). Interpreting pronouns and connectives: Interactions among focusing, thematic roles, and coherence relations. Language and Cognitive Processes, 15, 225-262.

Stewart, A. J., Pickering, M. J., \& Sanford, A. J. (2000). The time course of the influence of implicit causality information: Focusing versus integration accounts. Journal of Memory and Language, 42, 423-443.

Tanenhaus, M. K., Spivey-Knowlton, M. J., Eberhard, K. M., \& Sedivy, J. C. (1996). Using eye movements to study spoken language comprehension: Evidence for visually mediated incremental interpretation. In T. Inui \& J. L. McClelland (Eds.), Attention and performance XVI: Information integration in perception and communication (pp. 457-478). Cambridge, MA: MIT Publishing.

Traxler, M. J., Bybee, M. D., \& Pickering, M. J. (1997). Influence of connectives on language comprehension: Eye-tracking evidence for incremental interpretation. The Quarterly Journal of Experimental Psychology, 50, 481-497.

Van Berkum, J. J. A., Koornneef, A. W., Otten, M., \& Nieuwland, M. (2007). Establishing reference in language comprehension: An electrophysiological perspective. Brain Research, 1146, 158-171.

Van Herten, M., Kolk, H. H. J., \& Chwilla, D. (2005). An ERP study of P600 effects elicited by semantic anomalies. Cognitive Brain Research, 22(2), 241-255.

Vonk, W. (1985). The immediacy of inferences in the understanding of pronouns. In G. Rickheit \& $\mathrm{H}$. Strohner (Eds.), Inferences in text processing (pp. 205-218). Amsterdam: North-Holland.

Vonk, W., \& Cozijn, R. (2003). On the treatment of saccades and regressions in eye movement measures of reading time. In $\mathrm{J}$. Hyönä, R. Radach, \& H. Deubel (Eds.), The mind's eye: Cognitive and applied aspects of eye movement research (pp. 291-312). Oxford: Elsevier. 